\title{
Instruction Manual for ORNL Tandem High Abundance Sensitivity Mass Spectrometer
}

\author{
David H. Smith \\ H. S. McKown \\ W. H. Christie \\ R. L. Walker \\ J. A. Carter
}

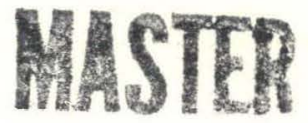

\section{OAK RIDGE NATIONAL LABORATORY}

OPERAILU BY UNION CARBIDE CORPORATION FOR THE ENERGY RESEARCH AND DEVELOPMENT ADMINISTRATION 


\section{DISCLAIMER}

This report was prepared as an account of work sponsored by an agency of the United States Government. Neither the United States Government nor any agency Thereof, nor any of their employees, makes any warranty, express or implied, or assumes any legal liability or responsibility for the accuracy, completeness, or usefulness of any information, apparatus, product, or process disclosed, or represents that its use would not infringe privately owned rights. Reference herein to any specific commercial product, process, or service by trade name, trademark, manufacturer, or otherwise does not necessarily constitute or imply its endorsement, recommendation, or favoring by the United States Government or any agency thereof. The views and opinions of authors expressed herein do not necessarily state or reflect those of the United States Government or any agency thereof. 


\section{DISCLAIMER}

Portions of this document may be illegible in electronic image products. Images are produced from the best available original document. 
Printed in the United States of America. Available from National Technical Information Service

U.S. Department of Commerce

5285 Port Royal Road, Springfield, Virginia 22161

Price: Printed Copy \$5.00; Microfiche \$2.25

This report was prepared as an account of work sponsored by the United States Government. Neither the United States nor the Energy Research and Development Administration/United States Nuclear Regulatory Commission, nor any of their employees, nor any of their contractors, subcontractors, or their employees, makes any warranty, express or implied, or assumes any legal liability or responsibility for the accuracy, completeness or usefulness of any information, apparatus, product or process disclosed, or represents that its use would not infringe privately owned rights. 
Contract No. W-7405-eng-26

ANALYTICAL CHEMISTRY DIVISION

\section{INSTRUCTION MANUAL FOR ORNL TANDEM"HIGH}

ABUNDANCE SENSITIVITY MASS SPECTROMETER

David H. Smith, H. S. McKown, W. H. Christie,

R. L. Walker, and J. A. Carter

JUNE 1976

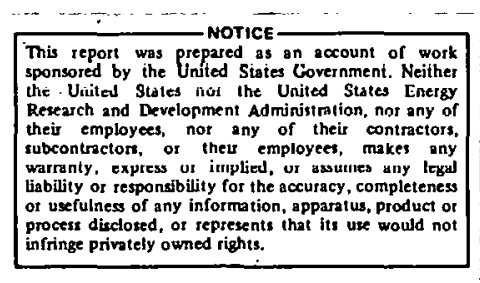

OAK RIDGE NATIONAL LABORATORY

Oak Ridge, Tennessee 37830

operated by

UNION CARBIDE CORPORATION

for the

ENERGY RESEARCH AND DEVELOPMENT ADMINISTRATION 
THIS PAGE

WAS INTENTIONALLY

LEFT BLANK 
ABSTRACT ......................... 1

INTRODUCTION . . . . . . . . . . . ........ 1

1. DESCRIPTION OF THE INSTRUMENT . . . . ........ 2

1.1 Overview ..................... 2

1.2 Vacuum System ................. 3

1.3 The Magncts . : . . . . . . . . . . . . 7

1.4 The Source and Sample Changer .......... 12

1.5 Data Accumulation .............. 15

2. CALIBRATION .................. 17

2.1 Multiplier ................... 17

2.2 Beam Width Measurement ............. 18

2.3 Integration of Samples............. 20

2.4 Determining Correction Parameters ........ 20

2.5 Daily Standard ................. 21

3. ROUTINE OPERATIONS .................. 23

3.1 Source Alignment . . . . . . . . . . . . 23

3.2 Cleaning the Source .............. 25

3.3 Contactor Construction and ATignment ....... 27

3.4 Filament Construction, Cleaning, and Alignment . . . 28

3.5 Loading Samples on Filaments ......... 33

3.6 Installing a Wheel of Filaments in the Instrument . . 33

3.7 Pumpdown Procedure .............. 35

3.8 Venting the Instrument ............. 35

3.9 Safety Interlocks ................ 37

3.10 Operation of the Isolation Valve ......... 38

3.11 Benzene Sample Reduction ........... 39

3. 12 Finding and Focusing the Ion Beam ........ 39

3.13 Taking Data .................. 43

3.14 Changing Samples ................ 44

3.15 Short Term Shut-down ............. 44

3.16 Long Term Shut-down ............... 46

3.17 If the Power Fails .............. 46 
4. MAINTENANCE OF THE VACUUM SYSTEM AND DETECTOR . . . . 47

4.1 Vacion Pumps ............... 47

4.2 0il Diffusion Pump .............. 47

4.3 Cleaning the Source Can . . . . . . . . . . 48

4.4 Changing Multipliers ............ 48

4.5 Leak Hunting .................. 52

5. ELECTRONICS ................... 54

5.1 Overview ................... 54

5.2 Mass Spectrometer Electronics ... . . . . . 54

5.2.1 Source Electronics .......... 54

5.2 .2 Magnet Electronics ........... 56

5.2 .3 Collcctor Elcctronics . . . . . . . 57

5.2.4 Sweep Control Electronics ......... 57

6. COMPUTER PROGRAMS ................ 63

6.1 Description of the Computer ........... 63

6.2 Disk Files ................... 63

6.2 .1 CHDATA .............. 63

6.2 .2 MSSAM ............... 63

6.2 .3 VCTSF。............... 64

6.2 .4 SPISO ............... 64

6.2 .5 MSBKP 。. .............. 64

6.2 .6 MSOUT 。................ 64

6.3 Overview of the Programs ............. 65

6.4 Program MSRUN = Bata Accumulation . . . . . : . . . 65

6.5 Program MS - Data Processing : . . . . . . 67

6.6 Statistical Treatment of the Data.......... 71

6.7 Auxiliary Programs: FILST, MSDAT, MSREP, DISPL . . 74

6.8 Subroutines: LINE, DATSW, FDATE, DISP1 ...... 75

7. SUMMARY ......................... 77

REFERENCES ........................ 80

APPENDICES 。. . . . . . . . . . . . . . . . . 81

1. Vacuum Components Obtained from Commercial Vendors . 82

2. Electronic Components Obtained from Commercial Vendors. 84 
Page

3. Addresses of Commercial Vendors . . . . . . . 85

4. Vacuum Component Print Index . . . . . .. . . 86

5. ORNL-Built Electronic Components Print Index .. . . . 87

DISTRIBUTION LIST . . . . . . . . . . . . . . 88 
LIST OF FIGURES

Figure

Description

Page

1.1

Vacuum system layout .............. 4

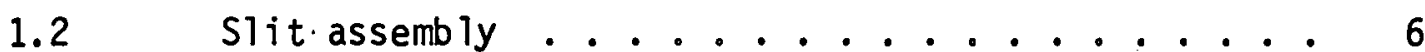

1.3 Magnet assembly ............. 8

1.4 Block diagram of magnet trim circuit....... 10

1.5 Plot of field strength vs. coil current ..... 11

1.6 Ion source mounted in mass spectrometer ..... 13

1.7 Sample wheel wi th filaments ......... 14

2.1 Multiplier calibration aids ......... 19

a. Typical multiplier response curve

b. Exalliple uf bedill width measurement

3.1 Thermal ion source ............ 24

3.2 Observations required in source alignment .... 26

a. Exit slit

b. Filament

3.3 Contactor assembly ............ 29

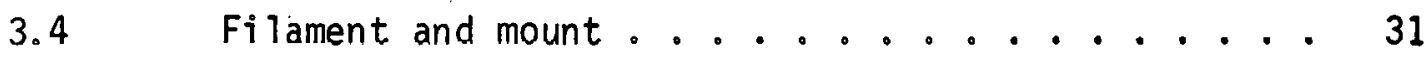

3.5 Sample wheel mounted for filament alignment check. . 32

3.6 Source and sample wheel assemblies mounted in the mass spectrometer............. 34

3.7 Schematic diagram of pumping system ...... 36

3.8 Effect of magnet adjusting on peak shape ..... 41

3.9 Effect of voltage drift on peak positions in subgroups ................ 45

4.1 Preparation of a multiplier for installation ....51

a. Four wires to be joined

b. Wires to be removed

5.1 Block diagram of electronics ......... 55

5.2 Sweep control panel ........... 58

5.3 Oscilloscope display panel ......... 59

7.1 Abundance sensitivity measurement . . . . . . 78 
ABSTRACT

This manual describes the physical characteristics of the tandeiii ilids's spectrometer built by Uak Ridge National Laboratory for the International. Atomic Energy Agency. Operating instructions are also given.

\section{INTRODUCTION}

The instrument herein described has been built especially for the International Atomic Energy Agency by members of the Mass and Emission Spectrometry Group of the Analytical Chemistry Division of the Oak Ridge National Laboratory. Specific requirements to be met include ability to run small samples, high abundance sensitivity, good precision and accuracy, and adequate sample throughput. The instrument is capable of runining uranium samples as smà 11 as $10^{-12} \mathrm{~g}$ and has an abundance sensitivity in excess of $10^{6}$. Precision and accuracy are enhanced by a special sweep control circuit. Sample throughput is 6 - 12 samples per day. Data are taken under computer control and processed off line by the same computer to give final reports. The data processing programs are written in a high level language (FORTRAN IV), which al lows modification by IAEA personnel to be implemented with relative ease. 
CHAPTER 1。 DESCRIPTION OF THE INSTRUMENT

\section{1" Overview}

The mass spectrometer built by the Analytical Chemistry Division of the Oak Ridge National Laboratory for the International Atomic Energy Agency is designed specifically for the isotopic analysis of heavy metals, in particular uranium and plutonium. It has two $90^{\circ}, 30 \mathrm{~cm}$ radius sector magnets which give an abundance sensitivity of $10^{\text {h }}$ to allow 1sotopes in the luw pilll range to be reliably analyzed. It is equipped with a pulse counting detection system that counts fndfvidual ions as they arrive at the detector; this a.l lows isotopic analysis of samples in the sub-nanogram range. The signal from the detector is fed into a Digital Equipment Corporation PDP-11 computer, and processing of the data is automatic. Instruments similar to this one, as well as others at ORNL, have been described by Cameron et al. 1

The abundance sensitivity of a mass. spectrometer describes its ability to measure minor isotopes that are adjacent to major ones. It is defined as the ratio of the ion beam intensity of the major isotope $M$ to the background current at the adjacent mass positions:

$$
\text { Abundance sensitivity }=\frac{\text { Ion current at mass } M}{\text { Ion current at } M \pm T} \text {. }
$$

Contributions to the background current come from detector noise and from scattering. Collisions between ions of mass $M$ and molecules of residual gases in the mass spectrometer cause the ions to gain or lose momentum and thus to deviate from the desired path in the magnetic field. Those that lose momentum appear on the low mass side of the peak, and some fraction of them will appear at the M-1 position. A smaller percentage of the ions gain momentum and appear on the high mass side of the peak. The number of gas phase collisions that occur is obviously pressure dependent. To minimize scattering and thus maximfze abundance sensitivity, it is necessary to have a vacuum below $1 \times 10^{-7}$ torr. The various parts of this spectrometer are connected by standardized $f l$ anges and gaskets, which are available from several manufacturers of high-vacuum equipment. Only 300 series, non- 
magnetic stainless steels are used. The vacuum system of the instrument is therefore of all-metal construction and is bakeable to $200^{\circ} \mathrm{C}$ except for the multiplier seal, which is soft solder.

\subsection{Vacuum System}

Figure 1,1 shows the physical layout of the vacuum system. Item 1 is the housing for the sample changer and source; it is known as the source can. A viewing port, through which the position of the filament is observed and its temperature read, is mounted on one side of this can. $A$ rotary-motion feed-through to rotate the sample wheel is mounted on the can opposite the viewing port. Both the viewing port and rotary motion feedthrough are attached to demountable stainless steel flanges. High voltage for the source enters the vacuum system via high-voltage metal/ceramic feedthroughs that are welded to the can. The front of the source can, through which daily changes of the sample wheel are made, is sealed with a circular Pyrex plate $1.27 \mathrm{~cm}$. thick. Two concentric Viton 0-rings make the vacuum seal to the plate; the space between the two is mechanically pumped to help secure the ultra-high vacuum. The source housing can be baked at $200^{\circ} \mathrm{C}$ without risk of vacuum failure.

A $15 \mathrm{~cm}$ ( 6 in.) flange is affixed to the bottom of the source can; an adaptor collarbolts to this flange and to the $20 \mathrm{~cm}$ ( 8 in.) gate valve below it. This gate valve serves to isolate the $140 \mathrm{r} / \mathrm{sec}$ ion pump when the source is vented. The roughing system is isolated from the high-vacuum system by a Varian all-metal right-angle val.ve. A Varian/NRC Ion gauge is. mounted on the adaptor for pressure measurement.

Item 2 of Figure 1.1 is a valve used to isolate the analyzer region from the source region. It is a Granville-Phillips $1.27 \mathrm{~cm}$., 180 , allmetal valve capable of allowing pressures below $10^{-9}$ torr to be maintained on the vacuum side while the other side is at atmospheric pressure. This valve is necessary to prevent venting of the analyzer region, with its sensitive electron multiplier, during the daily change of samples in the source region. The valve is accurately aligned and mounted on a $20 \mathrm{~cm}$ ( 8 in.) flange, on the other side of which the source is mounted. The 
ORNL-DWG. $70-9175$

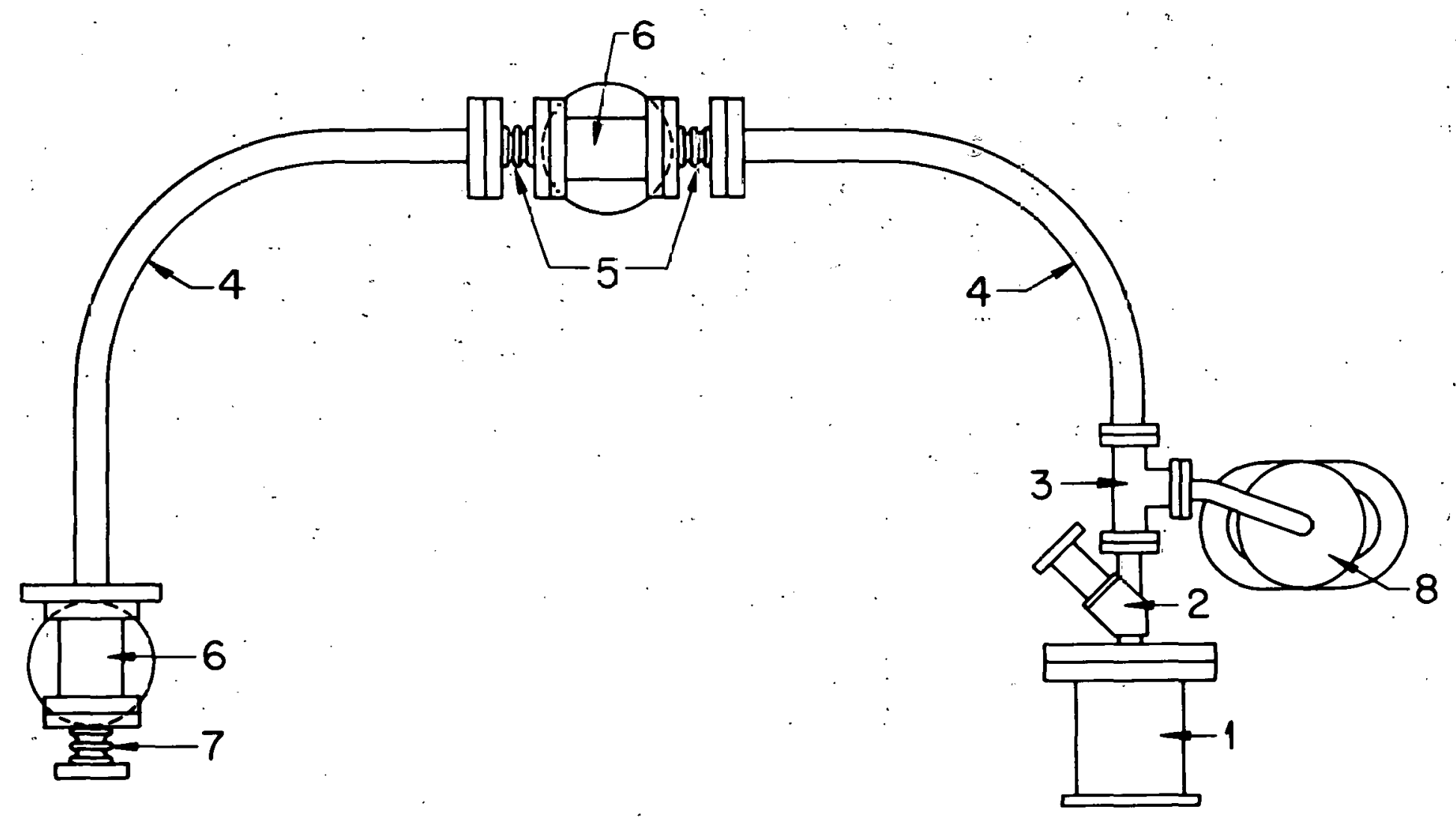

Fig. 1.1 Vacuum sys tem layout. 
analyzer end of the valve unit is terminated by a rotatable $7.0 \mathrm{~cm}$ flange. The entire valve unit is readily replaceable if it should begin to leak.

A cross ( $i$ tem 3 ) is bolted to the analyzer end of the valve unit to connect to a $30 \mathrm{l} / \mathrm{sec}$ ion pump and to provide a vacant port to the vacuum system. Following the cross is the first stage analyzer tube (item 4). Analyzer tubes are made of rectangular, seamless, OFHC copper wave guide. Each end is fusion-welded to a stainless steel flange. This welding technique does not require the use of a flux and gives a strong, reliable, leak-free seal. The tubes are gold plated on the inside to prevent the formation of oxides.

The performance of a two-stage mass spectrometèr is inherently dependent on the ion-optical alignment of the source, center slit, and collector slit. If the all-metal vacuum system were completely rigid, such alignment would be dependent on very accurate and costly machining of the various components. The copper analyzer tubes in particular are extremely difficult to align precisely. To avoid this problem, a flexible stainless steel bellows (item 5 ) is mounted after the first stage analyzer tube. The bellows is welded to two $11.4 \mathrm{~cm}$. flanges, one of which is rotatable. This arrangement allows complete freedom for alignment in all directions and is used to compensate for inevitable errors in machining.

Following the bellows is a slit housing can (item 6), which is provided with a pump-out port for mounting a $30 \mathrm{1} / \mathrm{sec}$ ion pump. The slit can houses a slit assembly, which is shown in Figure 1.2. All slit parts are gold. plated to ensure good electrical conduction and prevent charge build up, which would interfere with the ion optics. The two slit edges are independently adjustable and moved by micrometer drivers operating through a bellows seal; the drivers are attached to demountable flanges. Thus, both the width and position of the slit may be changed at will from outside the vacuum system. The slits are set at $0.038 \mathrm{~cm}(0.015 \mathrm{in}$.$) for the normal beam$ width of $0.017 \mathrm{~cm}(0.007 \mathrm{in.})$.

A single-stage spectrometer has its detector assembly mounted on this slit can. In a multi-stage spectrometer, the slit can is followed by a bellows and second analyzer tube similar to those already described. The 
ORNL-DWG. $70-10.964$

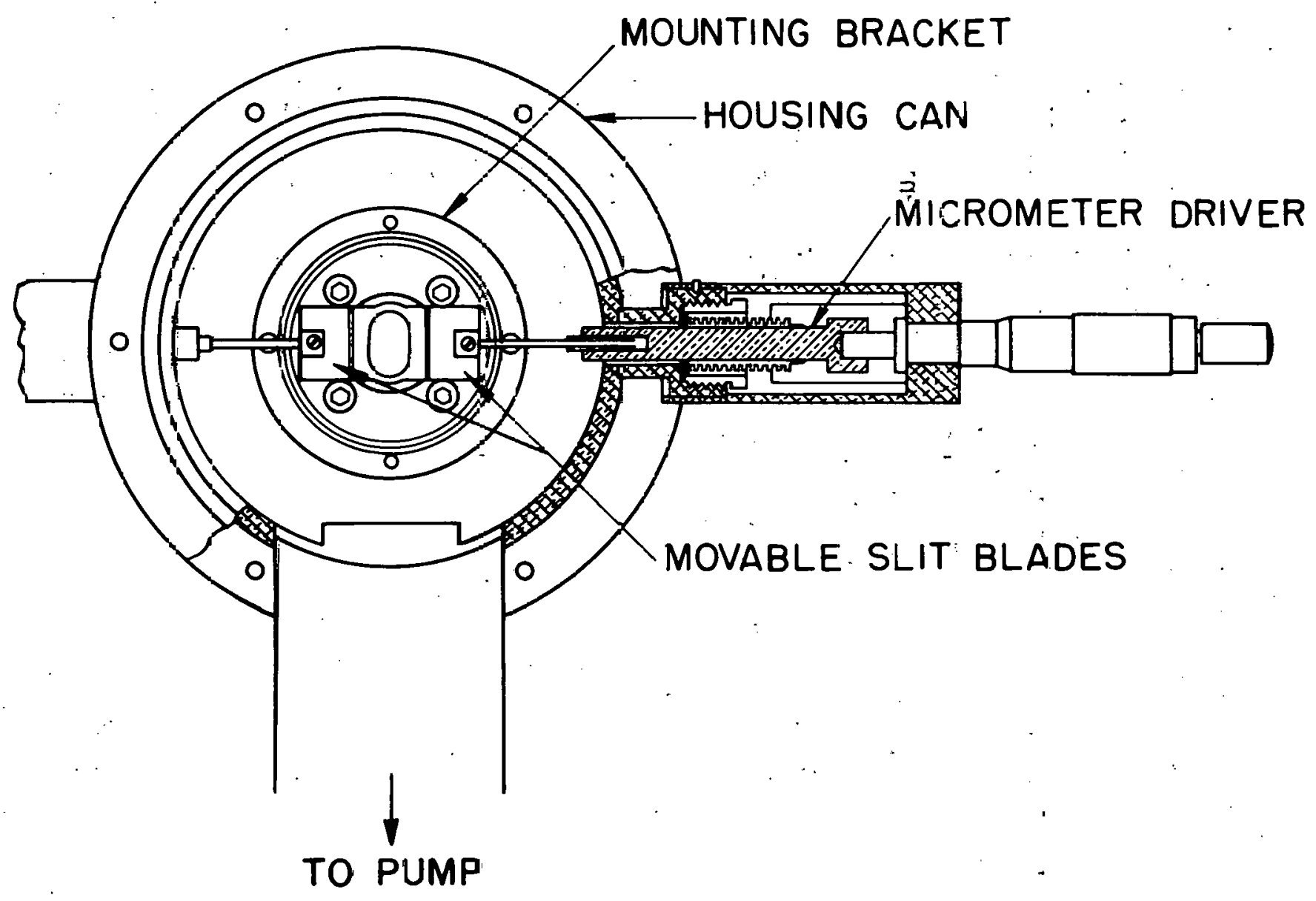

Fig. 1.2 slit assembly. 
two analyzer tubes are not interchangeable because of differences in flanges and length. The second stage tube is followed by a slit can identical to that al ready described.

The electron multiplier detector is contained in a housing (item 7) that mounts directly on the slit can. The multiplier is soft-soldered to a $\mathrm{n} 11.4 \mathrm{~cm}$ flange that bolts directly to the housing. A flexible bellows assembly allows the multiplier to be positioned so that the ion beam will fall on that portion of the first dynode that gives linear response to assure flat-topped peaks. A baffle is inserted between the $60 \mathrm{l} / \mathrm{sec}$ ion pump nearest the multiplier and the slit can to prevent ions generated by ul traviolet radiation from the ion pump from reaching the first dynode of the multiplier and causing unwanted background current.

The vacuum system is first evacuated to about 0.2 torr by a mechanical pump; a Varian M-2 oil diffusion pump is used for pressures between 0.2 and $1 \times 10^{-4}$ torr. At pressures below $10^{-4}$ torr, the source region is pumped by a Varian $140 \mathrm{l} / \mathrm{sec}$ Vacion pump. The analyzer region is pumped by Varian Vacion pumps (number 8 in Figure 1); in addition to the pump mounted on the cross (item 3), one pump is mounted under each slit assembly of the system. UI timate pressures in the analyzer region, which is vented only when a multiplier change is necessary, are below $10^{-10}$ torr. Ultimate pressures in the source region are about the same, but are seldom achieved because the daily sample change requires venting to atmosphere. Working pressures in the source region are about $1 \times 10^{-8}$ torr. Approximately two hours are required to pump down from atmospheric pressure to operating pressure. Figure 3.7 is a diagram of the pumping system.

\subsection{The Magnets}

The magnets are modified versions of the Knolls Atomic Power Laboratory design. ${ }^{2}$ The top yoke has been redesigned to make the $1.90 \mathrm{~cm}$ gap between the pole pieces more readily attainable. The top yoke is secured to the vertical surface of the side yoke (instead of to the top as in the KAPL design), as shown in Figure 1.3 . The gap is set to $1.90 \mathrm{~cm}(0.75 \mathrm{in}$.) with carefully machined spacers before final tightening of the yoke assembly. 
ORNL-DWG. 70-9161

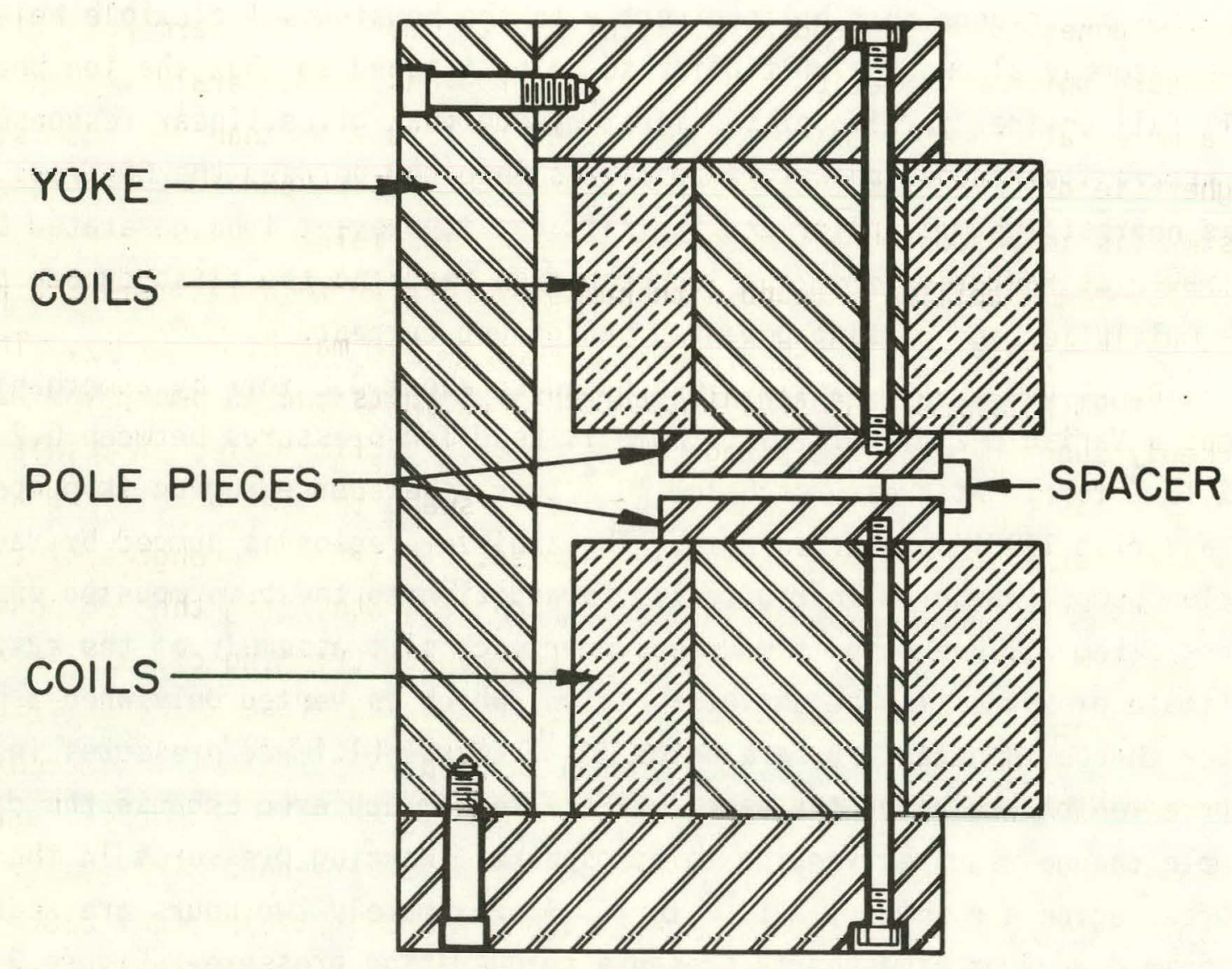

Fig. 1.3 Magnet assembly. 
This ensures a uniform gap, necessary for a homogeneous magnetic field, that does not require high-tolerance machining of the yoke pieces. The magnets are designed to give a central ion path with a radius of $30 \mathrm{~cm}$ (12 in.).

The magnet yokes and pole pieces are made of Armco ingot iron. The iron is annealed before and after machining to improve its permeability and to ensure uniform magnetic fields. Armco iron has, in general, proven to be a more satisfactory material for magnet construction than SAE 1010 steel. $\mathrm{Higher}$ fields are attainable before saturation occurs, and there is less hysteresis in responding to a change of magnetic field.

The field coils are wound with number 8 Formvar insulated wire to produce coils with a resistance of about 3 ohms dc per magnet assembly. These coils require low voltage and high current (20 volts and 13 amps) and are markedly superior to high-voltage coils (500V). Difficulties of insulation are much easier to overcome, and circuits to sweep the magnetic field are much simpler when low-voltage coils are used. The field strengths of the two magnets can be adjusted relative to each other to bring the ion beam to the precise path desired. A diagram of the magnet trimming circuit is given in Figure 1.4. Low-voltage, transistorized power supplies are commercially available; a Hewlett-Packard model $6268 \mathrm{~B}$ is supplied with the instrument.

Figure 1.5 is a typical plot of the field strength versus coil current for one of the magnets. The magnets are operated at about 7500 gauss, which requires an ion-accelerating voltage of 9 to $10 \mathrm{kV}$ for mass 238 .

Each magnet assembly weighs about 1350 ki lograms and thus requires substantial mounting apparatus; a pier of solid concrete is used. The pier is $70 \mathrm{~cm}(28 \mathrm{in}$.$) wide and 52 \mathrm{~cm}(21 \mathrm{ino})$ high. The pier is in one piece, $168 \mathrm{~cm}$ long. The magnets themselves rest on a track made of two parallel steel I-beams, which in turn rest on the concrete piers. The I-beams are bolted to the pier to fix them in position and are accurately leveled by use of a cathetometer before grouting. Each magnet is provied with an assembly that allows it to be moved at an angle 45 degrees to the I-beam when adjustments in position are necessary during the initial alignment of the instrument. 
ORNL-DWG. 70-9160

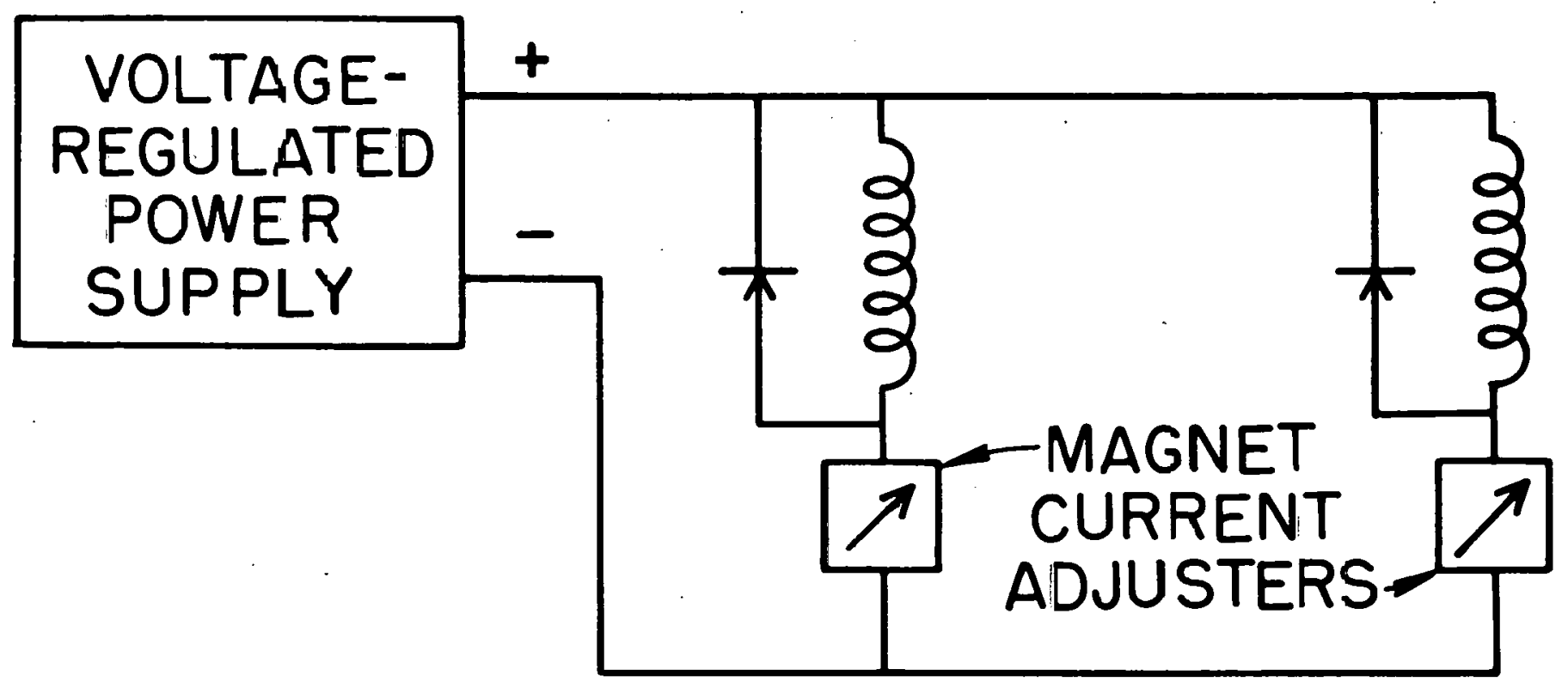

Fig. 1.4 Blcck diagram of magnet trim circuit. 


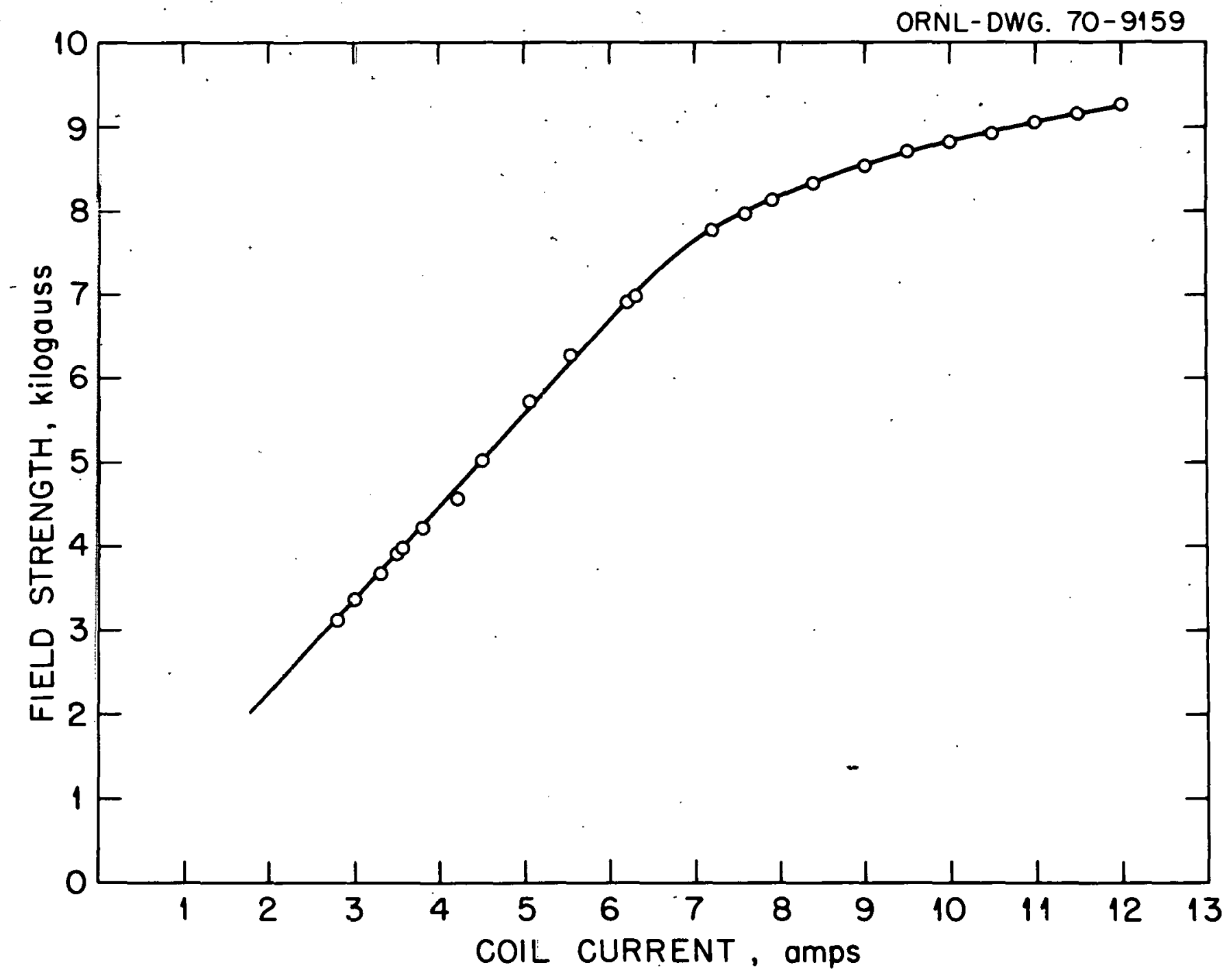

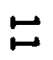

Fig. 1.5 Plot of field strength vs. coil current 


\subsection{The Source and Sample Changer}

The ion sources used in this spectrometer are modifications of the thick-lens source first developed by Nier. ${ }^{3}$ A source constructed according to the original design is subject to arcing at potentials greater than several kilovolts. The spacing and insulation of the source have been modified to make operation at voltages up to $15 \mathrm{kV}$ practicable. A drawing of the source is shown in Figure 3.1. Plates to focus the beam in the $Z$ direction (perpendicular to the floor) have been added between the two defining slits. Source parts are made of non-magnetic, 300 series stainless stee 1. The insulating spaçers are made of $96 \%$ alumina.

Precise alignment of the various parts of the source is crucial to successful operation. Once the sources have been properly aligned, there is no interchange of pieces between them. Careful visual inspection, particularly of the two defining slits, is necessary to ensure good ion transmission through the source. The height is maintained at $5.40 \pm 0.13$ $\mathrm{cm}$ ( $2.125 \pm 0.005$ inches). The top plate is kept parallel to the bottom plate to within $0.008 \mathrm{~cm}(0.003$ inches) to eliminate focusing problems. Figure 1.6 is a photograph of a source mounted in a spectrometer. The rotary motion driver that turns. the sample wheel is visible at the left.

A voltage divider keeps each plate at the correct potential with respect to that of the case (top) plate. Variable potentiometers allow adjustment of these voltages to bring the maximum ion intensity onto the detector. A combination of a John Fluke model 410B $10 \mathrm{kV}$ power supply and an ORNL-designed sweep amplifier is used to provide the voltage for the source. The fluke supply furnishes an adjustable constant potential; the sweep amplifier provides the additional step voltage function required to scan the mass spectrum. The potential to be scanned is adjustable from 0 to 500 volts. In the uranium region, this is sufficient to sweep about 10 mass positions.

The sample changer has been described by Christie and Cameron. ${ }^{4}$ It is basically a wheel upon which can be mounted six sample filaments. It is driven from outside the vacuum system by an U1tek rotary-motion feed-through. Protective shields prevent cross contamination between samples. Figure 1.7 is a photograph showing an assembled wheel. 


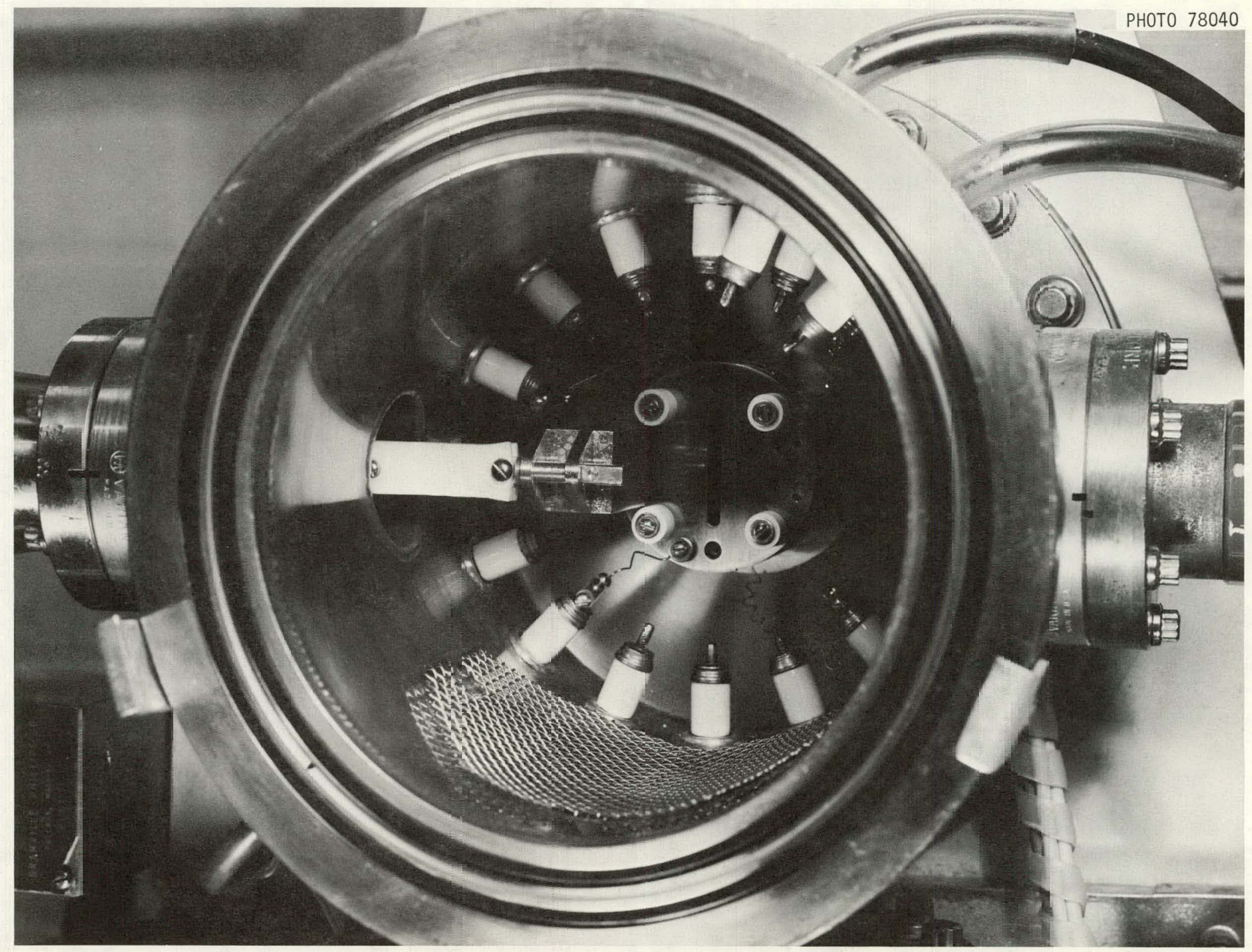

Fig. 1.6 [on source mounted in mass spectrometer. 


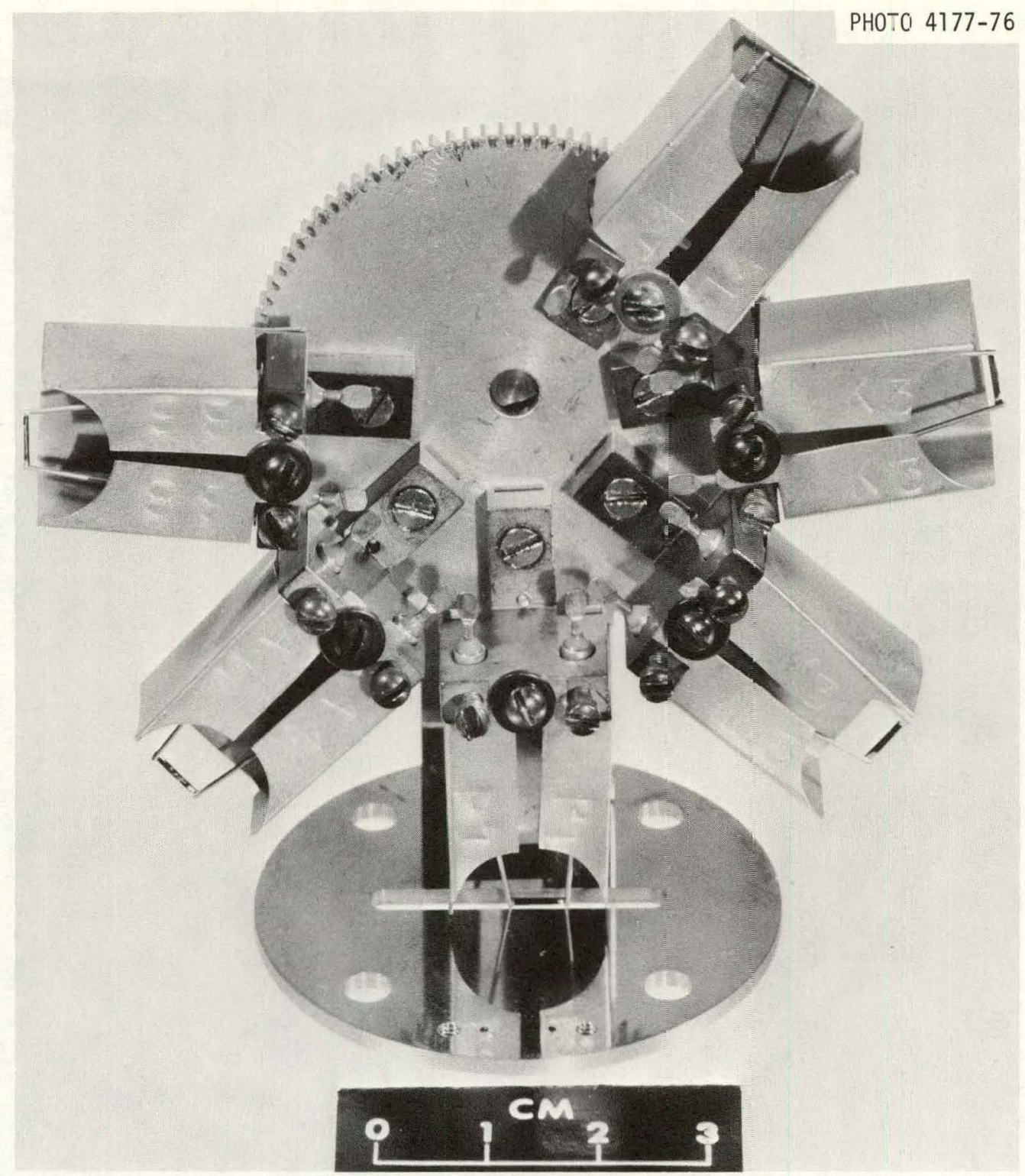

Fig. 1.7 Sample wheel with $=i$ laments. 
The filaments are rhenium canoes and are described in detail later (Section 3.4). The position of a filament relative to the source is indicated in Figure 3.1. The filament is heated by a power supply of ORNL design, capable of maintaining it at a constant temperature for several hours. This supply generates current regulated dc. Current regulation is necessary to compensate for variations in resistance as the filament is moved through the contactor.

\subsection{Data Accumulation}

To scan a mass spectrum there must be some means of changing the mass being focused on the detector. There are two ways of doing this in a conventional mass spectrometer: by sweeping the accelerating voltage of the ion source or by sweeping the magnetic field. The type of sample and the mass range to be scanned determine which technique is applicable in a given case. In general, voltage scanning is used when the mass range to be covered is small, as in most isotopic analyses; magnetic scanning is used when the mass range is large, as in most organic analyses. Voltage scanning is used when the same mass region is to be scanned repetitively, with the data accumulating from sweep to sweep; the voltage range covered in each scan is identical. Magnetic scanning does not readily lend itself to this type of data collection since it is very difficult to synchronize the tracking of the two magnetic fields of a tandem instrument well enough to keep the ion beam impinging on the first dynode of the multiplier. Lagergren and Stoffels ${ }^{5}$ have reported successfully scanning the second magnetic stage of a three-stage mass spectrometer with auxiliary "tickler" coils.

The detector is an RCA type $6810 \mathrm{~A}$ electron multiplier that has not been cesium activated. The multiplier has 14 stages and a maximum gain of about: $10^{6}$. The dynodes are made of a beryllium-copper alloy, which is a marked improvement over the silver-magnesium alloy previously used. The berylliumcopper dynodes give a multiplier that is both longer lived and has less background current than the earlier multipliers with silver-magnesium dynodes . The average operational life span of a good multiplier is about one year. The average background of a multiplier operating at $3 \mathrm{kV}$ is 1-2 counts per 
minute. Voltage for the multiplier is provided by a John Fluke model 408B $6 \mathrm{kV}$. power supply. A mu-metal shield surrounds the multiplier and prevents stray magnetic fields from affecting the focusing properties of the dynodes.

For isotopic analyses, ion pulse counting is used to provide the maximum sensitivity with respect to sample size. Individual ions impinging on the first dynode of the multiplier generate pulses that are amplified by two ARL model 104550 preamplifiers before being passed through an ORTEC model 436 discriminator to an ORNL-built high speed 15 bit scaler. From the scaler, the signal is passed to a 15 bit latch memory where it is held until the computer is ready to accept it. Further description of data accumulation is given in Chapters 3, 5, and 6 . 
CHAPTER 2: CALIBRATION

\subsection{Multiplier}

The instrument is equipped with an RCA-type 6810 14-stage multiplier. It is operated in pulse-counting mode and should have a gain of about $10^{6}$. The cost of these multipliers in 1976 was $\$ 225$ each. A reasonable reserve to have on hand would be 3 multipliers. The following phraseology should be used to order multipliers: Electron multiplier assembly, Type 6810, activated, sealed, and exhausted, but without base or photocathode, RCA C7187K or approved equivalent. Multipliers can be ordered from:

RCA, Electronic Components and Devices

New Holl and Avenue

Lancaster, Pa. 17604, USA

Installation of multipliers is covered in Section 4.5. The first task upon installation is to verify that it has reasonable operating characteristics. The background noise level should be checked. A newly installed multiplier will usually be noisier than a well-conditioned one, but an initial count rate (after standing in vacuum with the voltage on overnight) should be less than 10 counts per minute. If the background count rate is significantly greater than this, it probably means that either a noisier than average multiplier will have to be tolerated or another new one installed. It is probably worth waiting a week or two to see if an initially noisy multiplier quiets down to the normal 1-3 counts per minute background. If no counts at all are seen initially, the multiplier may have been wired improperiy. Check for an incorrect or bad solder connection. Occasionally a multiplier will have a shorted dynode and have to be replaced.

After initial conditioning by leaving the multiplier at $3 \mathrm{kV}$ overnight, the first step is to impinge an ion beam on to it. An NBS standard is recommended for all multiplier testing; preferably NBS 010, NBS 020, NBS 030, or NBS 500. After focusing the source (Section 3.12), a plot of ion count rate versus multiplier voltage should be made. The multiplier should be operated at the low voltage side of the region of relatively linear response. A typical initial voltage is 2500-3000 volts. The response of a new multiplier 
should be checked every day or two and then periodically (every few months), or whenever trouble is suspected. It is important to operate on the "plateau" to obtain reproducible results. The absence of a plateau means that operation of the multiplier will be problematic because of difficulty in obtaining reproducible results: It may be necessary to replace it.

A curve of multiplier response vs position of the beam on the first dynode should now be made. This is done by opening the rear and center slits very wide (but not wide enough so that 235 . and 238 both fall on the collector) and scanning the beam across with the high voltage at a suitable sweep amplifier setting. A typical result is shown in Figure 2.1a. The slits should be closed to give the desired beam width, making sure that the beam falls on a region of linear response. to be sure of obtaining flattopped peaks. This operation is normally done by moving first one slit and then the other in convenient steps while observing the results on the oscil: los cope.

The multiplier should now be physically rocked by using the four knurled thumb screws located in the multiplier bellows mount. The count rate is monitored on the count rate meter, and the multiplier positioned to maximize signal intensity; the flat peak top should not be affected by this operation. There are two potentiometers on the multiplier divider that adjust the voltage between dynodes. These should also be adjusted to maximum count rate: using a plastic screwdriver since the potentiometer shafts are at high voltage.

\subsection{Beam width Measurement}

The mass spectrometer has a theoretical magnification of 1 , which means that the beam width at all focal points should be equal. If, for example, a source with an exit slit of $0.15 \mathrm{~mm}(0.006 \mathrm{in}$.) is in the instrument, the width of the beam at both the center and rear slits should also be $0.15 \mathrm{~mm}$. (If the beam is significantly wider at the final slit than at the source, the magnets have somehow become misaligned and should be correctly positioned.) 

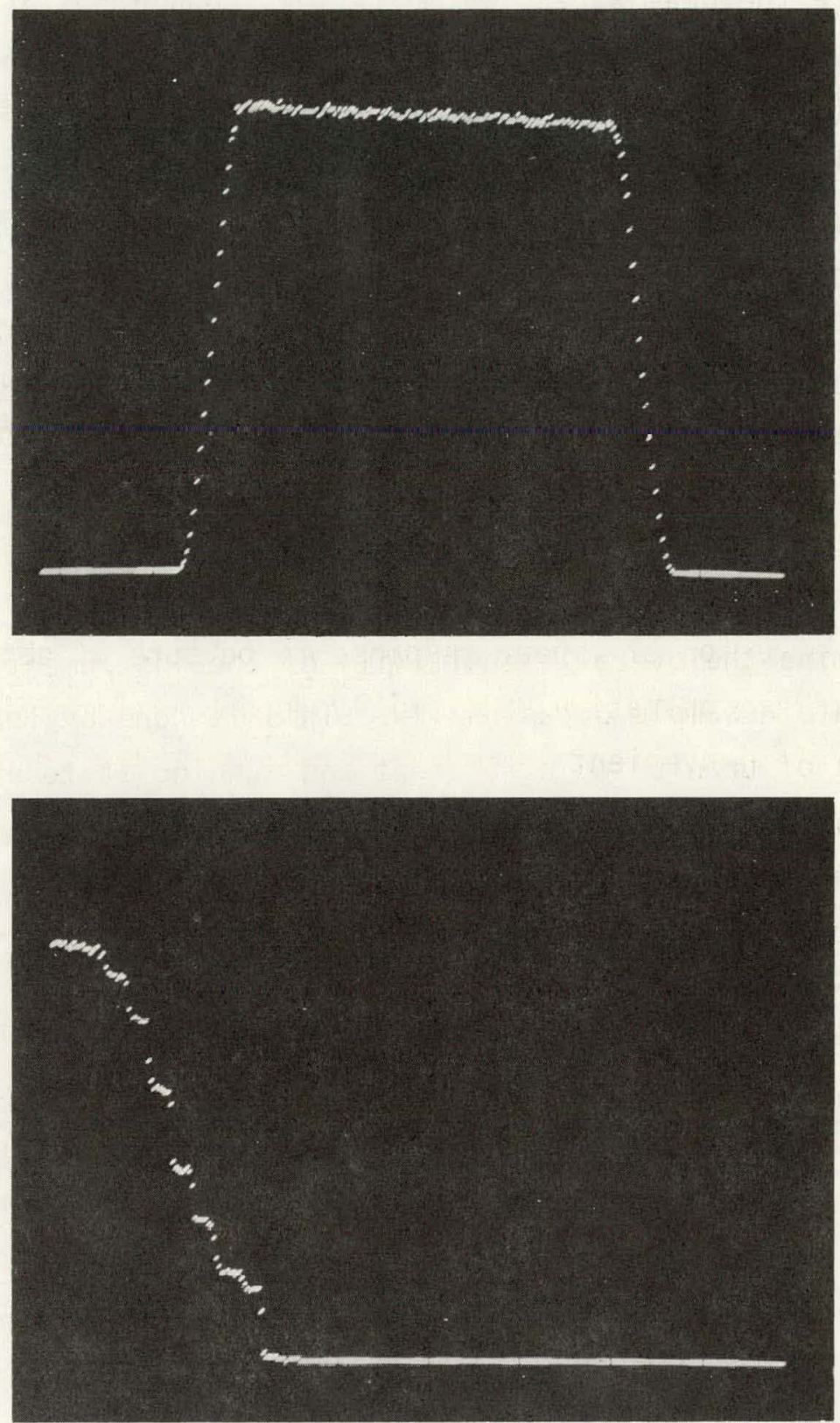

Fig. 2.1 Multiplier calibration aids.

a. Typical multiplier response curve.

b. Example of beam width measurement. 
To measure the beam width, which is most meaningful at the final slit, open one slit blade wide and position the other so that it is just off the beam (i.e. the signal is at full intensity $\left(\sim 10^{5}\right.$ counts per second), but the slit blade is very close to intruding into it). At regular intervals, turn the micrometer $0.03 \mathrm{~mm}(0.001 \mathrm{in}$.$) in until the in-$ tensity is reduced essentially to background. The number of steps required (displayed on the oscilloscope) is a measure of the beam width. A typical example is shown in Figure 2.1b, which shows a beam $0.018 \mathrm{~cm}(0.007 \mathrm{in.})$ wide.

\subsection{Integration of Samples}

To determine the overall sensitivity of the instrument, it is of interest to integrate a sample occasionally. This is done by loading a known amount $(<1 \mathrm{ng})$ of uranium on a filament and running it to exhaustion at a nearly constant count rate while focused on a single isotope. A high count rate $\left(4-5 \times 10^{-5}\right.$ counts $\left./ \mathrm{sec}\right)$ is recommended to reduce the time involved. Standard practice is to load NBS 950 and monitor mass 238, thus making isotopic corrections insignific.ant..

After correction for count. 1nss, typical sensitivities arc in the rarige of 1 ion detected for every b000 to 30,000 atoms loaded.

\subsection{Determining Correction Parameters}

Each time a new multiplier is installed, it. is neressary to determine its dead time and bias. To accomplish this, a number (usually a wheel of 6) of NBS 500 standards are run the day after installation; there is no point in running samples until the multiplier has been conditioned at least overnight at 3000 volts. The usual sample loading for NBS 500 standards is $100 \mathrm{ng}$, and they should be run at a high count rate $\left(>5 \times 10^{5}\right.$ counts per second) to obtain the best results. The dead time will be on the order of 25-35 nsec with an uncertainty of 1 or 2 nsec. The bias correction per mass can be fairly imprecise $( \pm 10 \%)$ because it is comprised of contributions from a number of sources. The discrimination caused by voltage scanning, mass 
discrimination of the multiplier, fractionation, and filament geometry are the major contributors. A bias correction of $0.2-0.5 \%$ per mass is normal; a bias correction greater than $0.5 \%$ usually means that it will be difficult or impossible to hold calibration with the multiplier in question. A second wheel of NBS 500 standards should be run two or three days after the first to verify the calibration parameters: The bias correction can frequently be refined after a week or two of routine operation by using the results of the daily standard.

\section{Section 2.5. Daily Standard}

An NBS standard should be chosen for daily analysis whose isotopic composition is close to that of the expected "average" sample. ORNL uses NBS 010; for safeguards purposes, NBS 020 or. NBS 030 are just as good. Analyzing one of these standards daily is necessary to maintain confidence in the calibration factors determined by analysis of NBS 500's (described in the previous section). A control chart should be maintained by plotting $235 / 238,234 / 235$, and $236 / 235$ for each standard. The table below outlines. the conditions that should be met to keep the instrument properly calibrated.

Example NBS 010:

$\begin{array}{ccc}\text { Ratio } & \text { True Value } & \text { L.E.\% } \\ 234 / 235 & 0.00538 & 2.0 \\ 236 / 235 & 0.00678 & 1.5 \\ 235 / 238 & 0.01014 & 0.7\end{array}$

If results for standards fall outside these limits on two or more consecutive days, the instrument is either out of calibration or some electronic malfunction is interfering with proper data taking.

Here are trouble-shooting guidelines to assist you when the results from the daily standard indicate trouble.

1) Change sources. A dirty source can cause excessive mass discrimination and poor precision. Run one or two daily control standards to check the new source. 
2) Check all voltages to the source from the divider panel. Occasionally a potentiometer goes bad or a lead comes loose from a source plate, causing it to float. Each successive plate should have a voltage range from equal to the plate above it to a few hundred volts below it. The $Z$ plates are an exception, and are at approximately 300 volts.

3) Check the plateau of the multiplier. This shifts to higher voltages as the multiplier ages. If it has drifted, run a control standard to eheck your calibration pardillelers at the new voltage. It is sometimes necessary to recalibrate the system by running a wheel of NBS 500 standards after increasing the voltage to accommodate a shift in the multiplier plateau.

4) If the precision seems all right but accuracy is poor, recalibrate the instrument by running a wheel of NBS 500 standards (Section 2.4.).

5) As the multiplier ages, it is necessary to increase the voltage (usually in 100-volt steps) from time to time to retain the necessary gain. As the voltage gets higher, and particularly as one approaches $n 000$ volts, the background noise of the multiplier Increases. "It is frequently the level of this background noise that necessitates a change of multipliers, although all other possibilities should be checked first.

6) A multiplier tends to lose gain as it ages. If the gain of a multiplier hernmes suspect, integrate one or two $1 \mathrm{ng}$ samples (Section 2.3) and, if the results indicate low gain, and if no other explanation seems feasible, it is probably time to change multipliers. However, it should be emphasized that changing sources will usually correct this particular problem: 
CHAPTER 3. ROUTINE OPERATIONS

\subsection{Source Alignment}

The overall sensitivity of the instrument is dependent on having a properly aligned source; indeed, the importance of this operation cannot be over-emphasized.

Figure 3,1 is a drawing showing two views of the source. Plates should not be interchanged between sources since there are slight variations between them. The four metal spacers separating the two collimating slits form matched sets which should not be broken up and which should stay with the sources they were originally part of. The al umina spacers may be interchanged at will.

Stacking of clean sources should be done with lint-free gloves of nylon or plastic to avoid contaminating them with fingerprints. When stacking a source, it is naturally important to be certain that the plates are in their proper sequence and orientation; these are clearly shown in Figure 3.1 except for the orientation imposed by high voltage leads. Be careful not to over-tighten the four screws as this will cause the threaded alumina rods to break; a gentle firmness is required.

Once the source is assembled, several checks should be made to ensure that it is properily aligned. The first of these involves verifying that the two focus plates are parallel. The jig supplied can be left between the $p$ lates while assembling the source, or it may be introduced afterwards. This is a non-critical measurement, and, once sufficient experience has been gained, can frequently be omitted entirely. The second test should be done each time a source is assembled. This involves verifying that the case (top) plate and the exit slit plate are parallel. Measurements of the two sides of the source should give heights that are within $0.08 \mathrm{~mm}(0.003$ in.) of each other. Small deviations from this range can usually be corrected by adjusting the tension on the four screws. Large deviations $(>0.2 \mathrm{~mm})$ will probably require taking the source apart and starting over again; some mixing of the alumina spacers is desirable before proceeding. 
ORNL- OWG. 76-3431
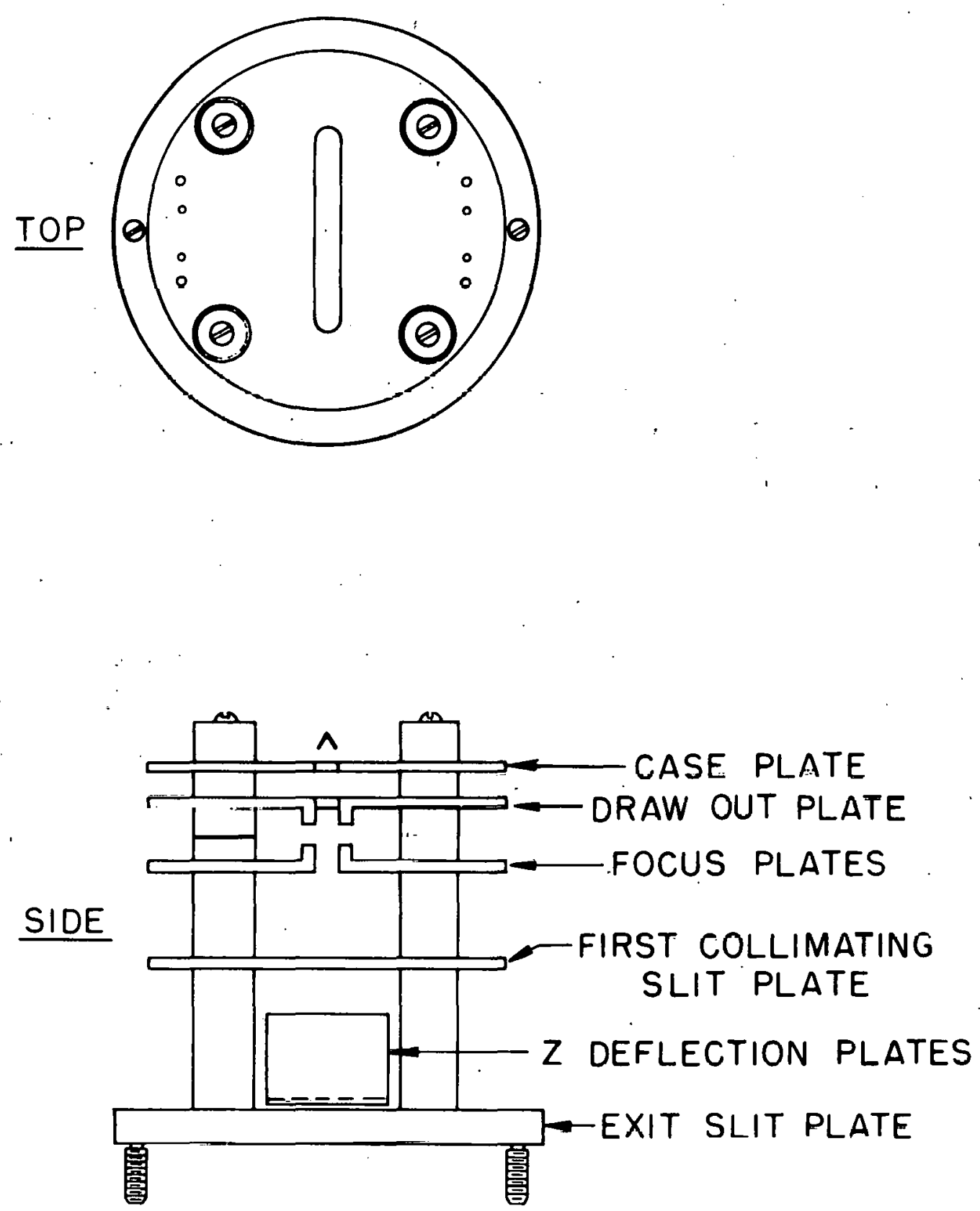

THERMAL

ION
SOURCE

Fig. 3.1 Thermal ion source. 
The most difficult and most crucial test is to verify that the two collimating slits are exactly superimposed. If they are not, the transmission (and hence sensitivity) of the instrument is drastically reduced. Unfortunately, no jig exists to assist in this operation, but with a little experience no great difficulties should be encountered. Remember that patience is a virtue! The best way to observe the orientation of the two slits with respect to each other is illustrated in Figure 3,2a. To ensure that the observer's eye is directly over the first slit, make the machining grooves of that plate bisect the arc of the larger slit in the draw-out plate. If the exit slit is then completely in view, the slits are properly aligned. If the slits intersect at some angle, or if only part (or none!) of the final slit can be seen, loosen the four screws and push the proper plate in the appropriate direction before tightening the screws again. This process should be repeated until all of the above tests are met. Before installing a source in the instrument, make sure that the two mounting screws, which are threaded for only part of their lengths, are turned all the way in so that no threads are engaged in the exit slit plate. Hold the source by the wheel bracket to mount it in the instrument.

CAUTION! When installing or removing a source, do not let the screws bind, which will happen if the threads become engaged with both the exit slit plate and the mounting $f l$ ange, or when the screws are loosened uneventy. Too much torque will break the screw, and it is not fun to try to

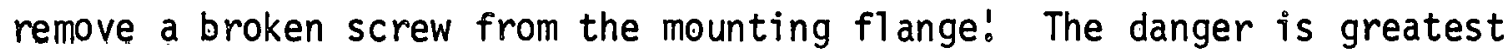
when removing a source. While performing this operation, keep a steady outward tension by pulling gently on the wheel bracket. If you feel the screw start to bind, tighten it a few turns and try again. Keep the screw and both threaded holes free of burrs by using the 4-40 tap and die when needed.

\subsection{Cleaning the Source}

All metal pieces of the source except the copper high voltage connectors and the brass wheel-mounting pin are made of $304 \mathrm{~L}$ stainless steel. The insulating spacers are made of alumina, $\mathrm{Al}_{2} \mathrm{O}_{3}$. 
ORNL-OWG. $76-3430$

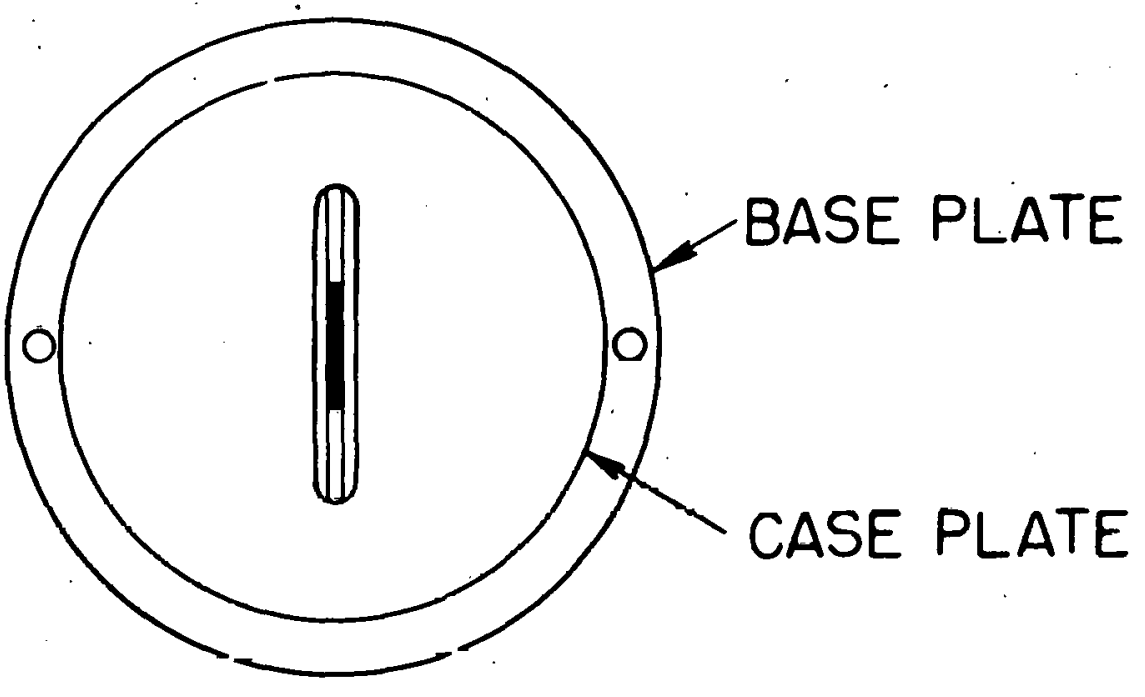

a

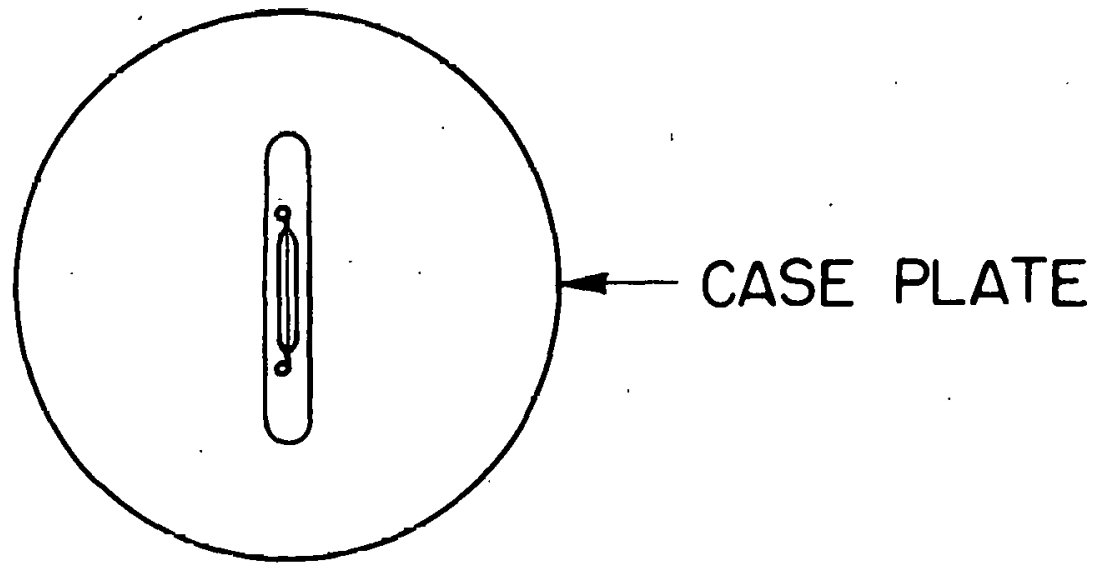

b

Fig. 3.2 Observations required in source alignment.

a. Exit slit.

b. Filament. 
The frequency with which sources need cleaning is largely a matter of individual judgment. If sensitivity seems low, or if beam stability is poor, the source probabily needs changing. A succession of poor results on the daily standard can also be indicative of a dirty source. An alternative approach, and the one we recommend, is to change sources at fixed intervals regardless of whether or not trouble has arisen. A reasonable interval is 1-4 weeks, depending on the number and kind of samples being analyzed. Samples loaded as solutions cause the source to become dirty rasler lhan lhose luaded as resin beads or wires.

A source must be completely disassembled before it can be cleaned. Buildup of Re and other material on the first two plates and on the first "slit plate is common. These deposits can be removed by gentle rubbing with wet (water or alcohol) 600 (U. S. grade) sandpaper. Stainless stee 1

$\therefore$ pieces are boiled for 30-60 min. in $1-1 \mathrm{HNO}_{3}$. Aiumina spacers are cleaned by heating for 30-60 min. in fuming chromic acid. Copper and brass pieces are cleaned by boiling in citric acid. All pieces are boiled 3 times for about $30 \mathrm{~min}$. each time in distilled water and put in an oven to dry. A source which resists cleaning by this method may be electropolished; this is especially helpful in removing oxide films. Clean sources, whether assembled or not, should be kept in plastic bags to reduce the chances of contamination.

Alumina spacers have a finite lifetime (2-3 years), but in 15 years of operation, ORNL has not: worn out a source plate.

\subsection{Contactor Construction and Alignment}

Electrical connection inside the vacuum system for heating the sample filaments is provided by a pair of spring loaded beryllium-copper contactors. Before a sample wheel is loaded into the instrument, it is important that the operator make sure that the individual sample filament contacts are aligned and will pass smoothly through a test pair of contactors. To perform this test, the filament wheel should be mounted on its bracket on a spare case plate, and the contactors should be mounted in their bracket, which is also affixed to the case plate. The wheel should then be hand 
turned and the operation of the contactors observed. If any of the individual filament contacts are misaligned, they should be straightened with a pair of needle-nose pliers until they slide smoothly through the contactors. This assembly, when ready for testing, should appear as shown in Figure 3.5. The alignment of the electrical contacts can be done at the same time the sample filaments are mechanically aligned with the case plate as described in Section 3.4. As one obtains experience with this system, it usually becomes unnecessary to do this alignment procedure, as a simple visual check of the assembled sampie filament wheol will reveal whether or not alignment is required. Figure 3.3 shows the contactors.

It is important, however, that the two spring loaded contactors always be examined for alignment any time a new pair is to be installed in the spectrometer. The entire sample wheel/bracket and contactor/bracket should be assembled as described above and the operation of the contactors observed. The circular base of the contactor into which the tungsten springs are mounted can be rotated to correct any misalignment. This rotation is performed with a pair of needle-nose pliers without loosening the set screws that secure the insulated base to the sontactor bracket. If rough or difficult operation of a pair of old contactors is encountered, this same test should be made outside the spertrnmeter. The sample wheel should never be forced through the contactors as this will probably result in irreparable damage.

Detailed drawings are provided (M2E90647-6) that give information concerning contactor construction as well as materials of construction.

\subsection{Filament Construction, Cleaning, and Alignment.}

Filament mounting blocks should bc cleaned after each use by the same technique used to clean sources (Section 3.2). Tungsten legs are available from commercial vendors and are used only once. The tungsten legs are spotwelded to the tantalum legs with the help of the filament jig. The feedthroughs are held in the filament blocks with set screws. To make filaments, fold a piece of the $6.3 \mathrm{~mm}(0.25 \mathrm{in}$.) Re strip over the end of a thin piece of metal; a 6-inch ruler (supplied) is ideal. Trim this double thickness in the micrometer shears to $0.75 \mathrm{~mm}(0.03 \mathrm{in}$.). 


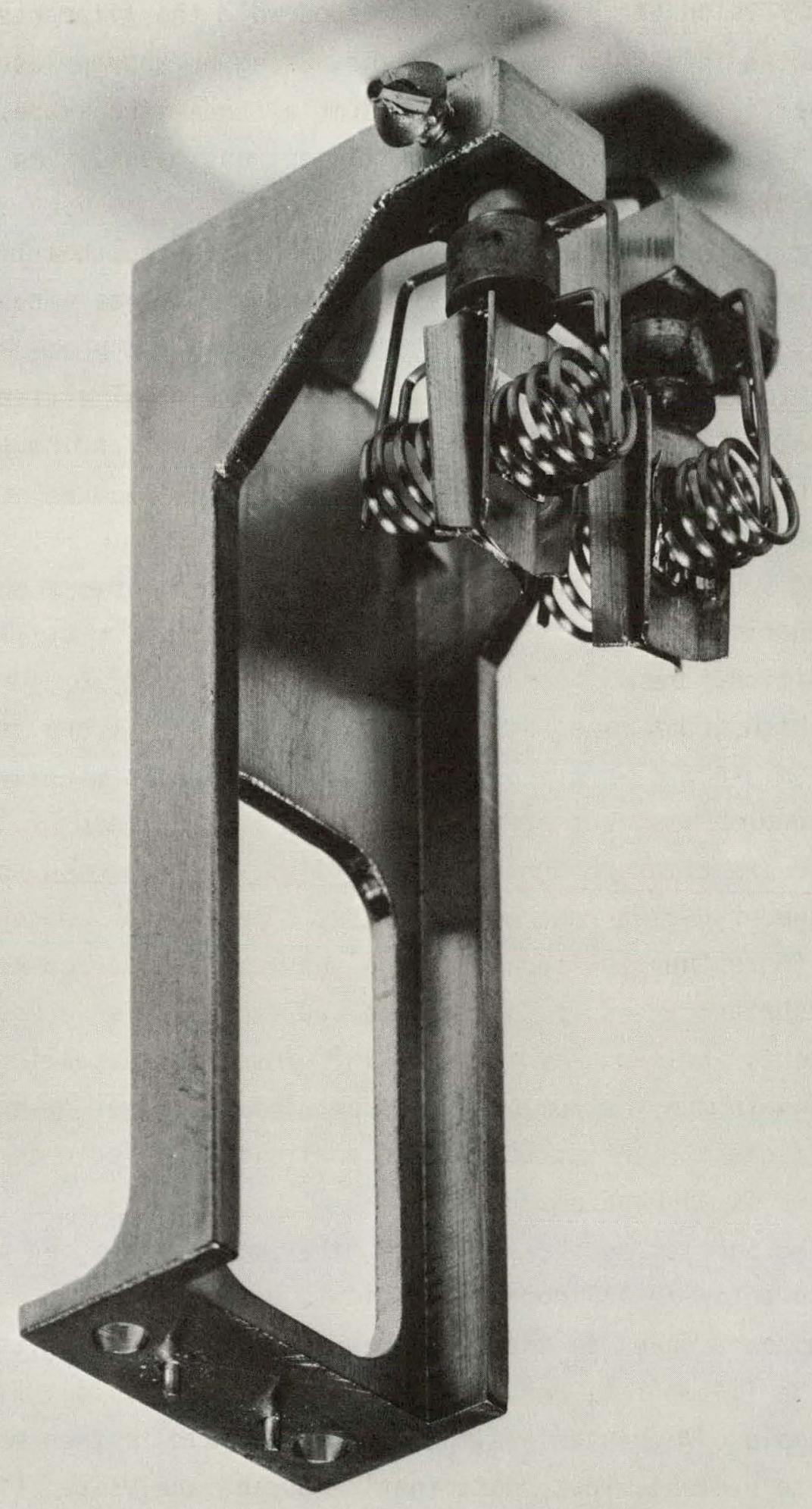

Fig. 3.3 Contactor assembly. 
Repeat ad nauseam. Using the jigs provided, spot weld the filaments to tungsten legs mounted in a filament block, and, using an appropriate tool, carefully open the filaments so that they assume a canoe-like shape. Figure 3.4 is a photograph of an assembled filament and mount. The filaments must now be cleaned.

Rhenium as it is received from the vendors contains enough surface contaminants to preclude reliable surface ionization analyses. These are larqely removed by baking the filaments at $2000^{\circ} \mathrm{C}$ for half an hour at a pressure of $210^{-7}$ torr. An NR.C 3115 auxiliary vacuum systeill is used at ORNL. It is pumped by a $12001 \mathrm{iter} / \mathrm{sec}$ oi 1 diffusion pump, and no problems ascribable to it have been encountered in the 6 years it has been in operation. Twenty filaments can be baked simultaneous ly.

Potassium and sodium are particularly insidious contaminants which can cause drastic reduction in ionization efficiency if present in sufficient quantity. In addition, the $\mathrm{K}_{6}{ }^{+}$ion falls at masses 234 and 236 and can cause spuriously high count rates at these positions during $U$ analysis. Uranium and thorium are always present in the Re metal; $U$ is usually low enough to cause no problems, but great. care should be exercised if tcmperatures above $1950^{\circ} \mathrm{C}$ are attained during an analysis. We recommend that $1900^{\circ} \mathrm{C}$ not be exceeded during routine operation. The Th problem can be extremely severe (more than $10^{6}$ count.s/ser $\mathrm{Th}^{+}$have been observed coming from a "pure" Re surface), and if Th is to be analyzed, it is necessary to certify the filaments individually first. This involves installing unloaded Re filaments in the instrument and ascertaining whether or not Th is present in sufficient quantity to ruin an analysis. Periodic certification for $U$ analysis is also necessary.

Before loading samples on the filaments, they must be aligned properly with the source to optimize ion optics. This is accomplished by mounting a set of filaments on a wheel on the spare case plate and bending the filament legs until the filament is centered in the case plate slit. Figure $3.2 b$ shows an example of acceptable alignment. A shield is then mounted on each filament to prevent cross contamination during analysis. Figure 3.5 is a photograph showing a completely assembled wheel in position for checking filament alignment. 


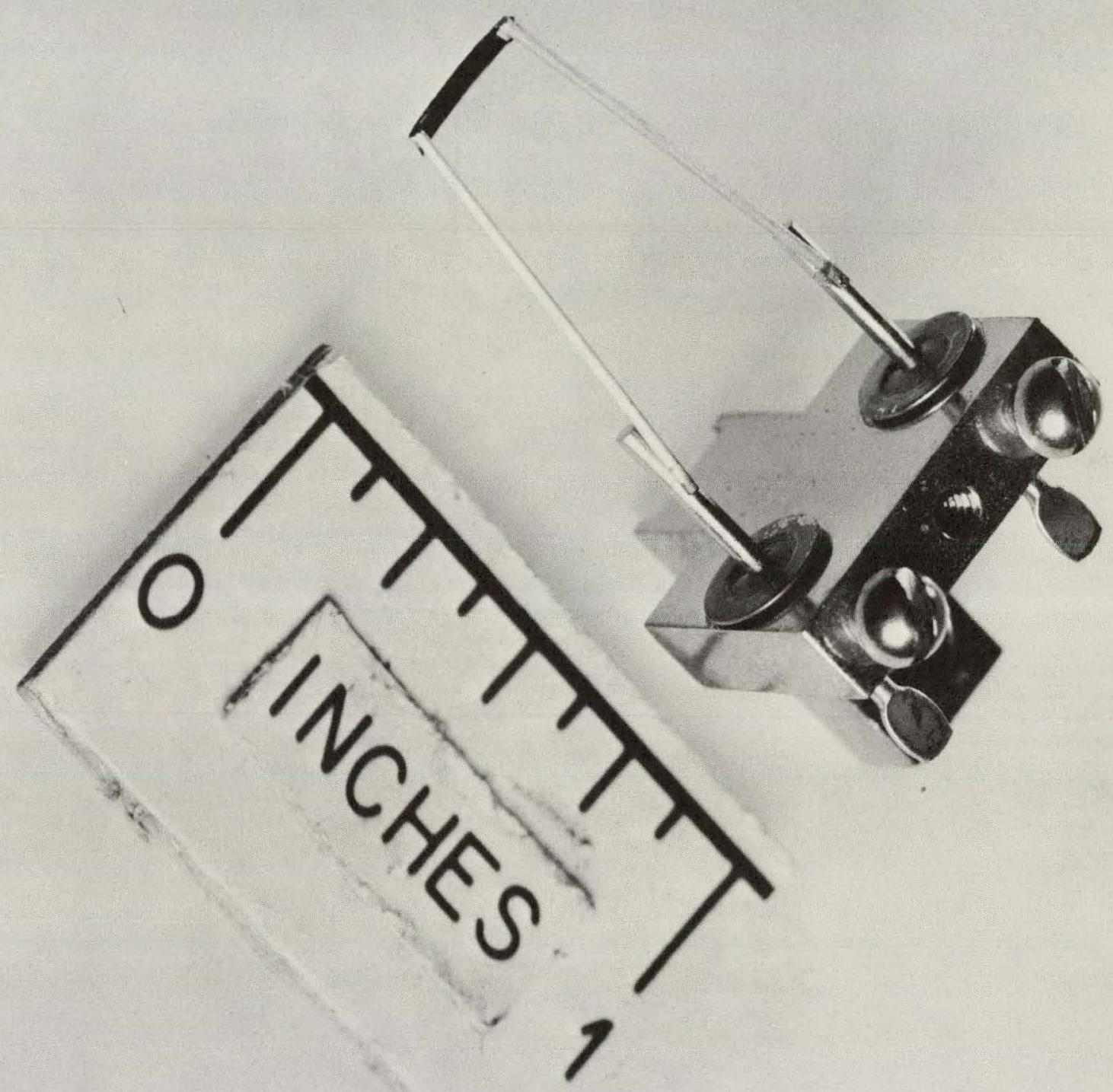

Fig. 3.4 Filament and mount. 


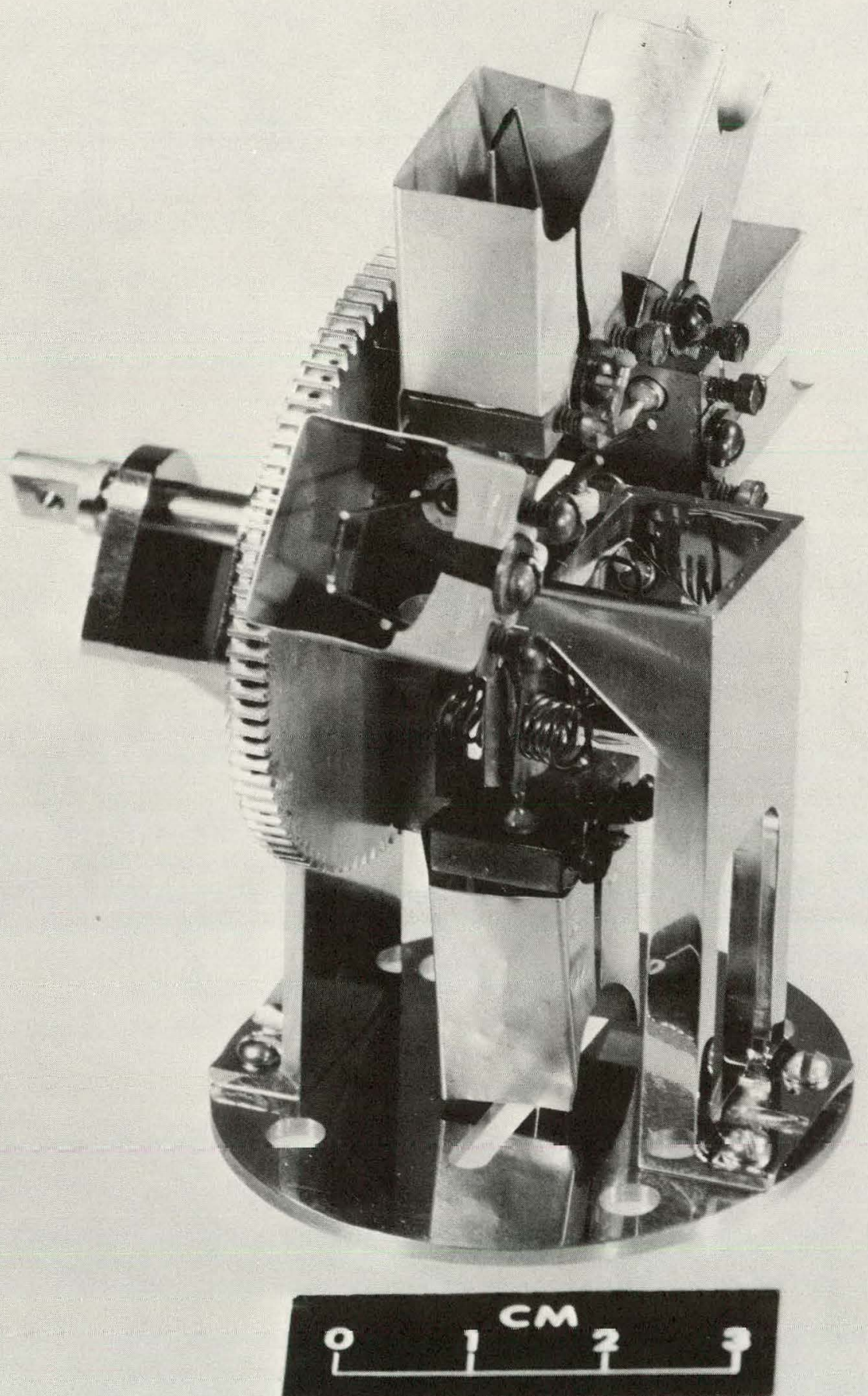

Fig. 3.5 Sample wheel mounted for filament alignment check. 


\subsection{Loading Samples on Filaments}

The sensitivity of the mass spectrometer is dependent on sample loading technique; the closer the sample is to a point source, the smaller the sample that can be run. The three common forms of samples are: 1) liquid solutions; 2) resin beads; 3) plated on wires.

If the sample is to be loaded as a solution, some care should be taken to achieve a concentration sufficient to give a uranium sample loading of 10-100 ng, or a Pu loading of 1-10 ng. Ionization of the sample is least efficient when it is loaded in this form. Recommended loading as solutions for NBS uranium standards is about $100 \mathrm{ng}$.

Resin bead loadings should have about $10 \mathrm{ng} \mathrm{U}$ and/or $1 \mathrm{ng} \mathrm{Pu}$ per bead. The technique has been described by Walker. ${ }^{6}$ An alternate loading technique is to plate the sample on a W wire and crimp the wire in the Re canoe. This is discussed in more detail by Cameron. ${ }^{7}$ To run lead and several other elements of high ionization potential and volatility, it is necessary to use a little silica gel on the filament as an evaporation retarding matrix. This technique is described in detail elsewhere. ${ }^{8}$

\subsection{Installing a Wheel of Filaments in the Instrument}

The wheel with 6 filaments mounted on it is installed in the instrument by tightening the screw in the wheel hub onto the brass driving pin of the rotary motion feedthrough. The contactor bracket is secured to the case $\mathrm{plate}$ by the two mounting screws, and the wheel is rotated through a complete revolution to make sure there is no binding between wiper blades and contactors. Never force the whee 1 through the contactors. If undue force is required, remove the contactors and go through the alignment procedure described in Section 3.3. Figure 3.6 shows how the complete assembly should look. Remember to connect the filament leads to their feedthroughs! Do not over-tighten these screws; this will prolong the life of the feedthrough. 


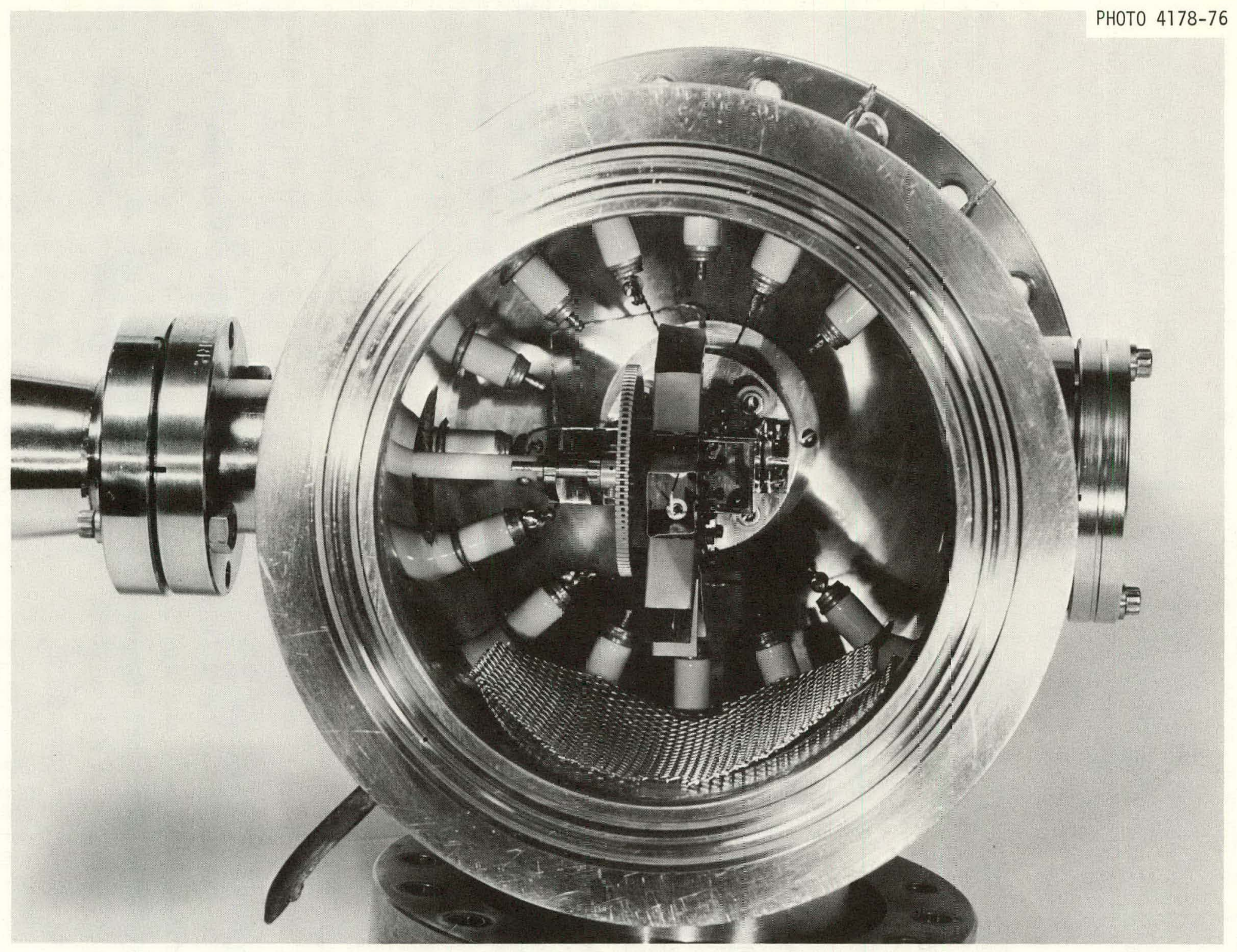

Fig. 3.6 Source and sample wheel assemblies mounted in the mass spectrome:er. 


\subsection{Pumpdown Procedure}

To evacuate the instrument, either the nose cone or the glass plate should be affixed to the front of the source can so that both 0 -rings are completely covered. In normal operation, the glass plate is used, but, if a set of particularly gassy samples is to be run, the nose cone can be used; liquid nitrogen in the small container will help maintain a lower pressure and reduce the likelihood of pressure bursts causing high voltage arcs in the source. After overnight pumping, operating pressure should be below $5 \times 10^{-8}$ torr.

Figure 3.7 is a "road map" of the pumping system. If the analyzer section is to be pumped down, be sure that the ion source is loosened or removed to allow reasonable throughput from the analyzer to the source region. Be sure the vent valve (item 3 in figure 3.7) is closed; open the mechanical pump valve (item 2) while holding the glass plate in position. When the pressure indicated on the mechanical pump thermocouple gauge reads $i 200 \mu$, open the diffusion pump valve (item 4 ) and close the mechanical pump valve. When the pressure indicated on the mechanical pump backing the diffusion pump is $v 200-300 \mu$, turn on the ion gauge. It is now that benzene reduction, if required, should be done (see Section 3.11).

When the pressure is below $10^{-4}$ torr, open the ion pump gate: valve and, once the pump has started pumping effectively, close the diffusion pump valve (item 4), and the source isolation valve (item 1). Open the mechanical pump valve (item 2) to obtain differential pumping between the two viton 0 -rings on the front of the source can.

\subsection{Venting the Instrument}

Each wheel change requires venting the volume between the ion pump gate valve and the analyzer isolation valve. ORNL has used dry air (air passed through a desiccant) for years with no adverse effects, but dry nitrogen would be perfectly acceptable. Inert gases should not be used because of the low pumping capacity of ion pumps for them. 


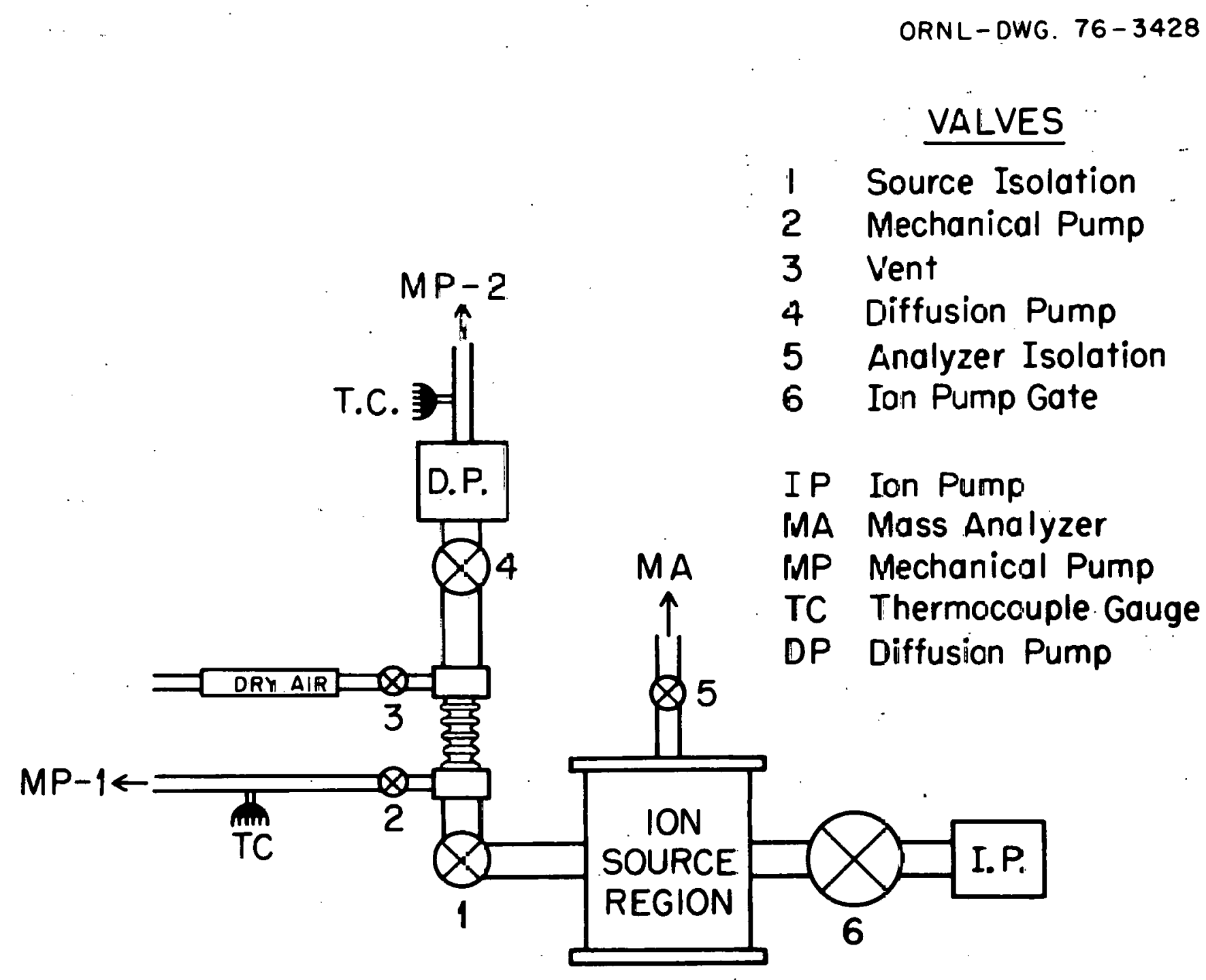

Fig. 3.7 Schematic diagram of pumping sys Łem. 
Venting procedure:

1) Make sure analyzer isolation valve (item 5 in Figure 3.7 ) is closed-you'll destroy a multiplier if it isn't!. (See Section 3.9).

2) Turn off source high voltage.

3) Turn off filament power supply.

4) Turn off sweep amplifier.

5) Turn off any other source of voltage that may shock you.

6). Turn off ion gauge.

7) Close the ion pump gate valve to isolate the $140 \mathrm{l} / \mathrm{sec}$ ion pump.

8) Make sure again that isolation valve is closed!

9) Close the mechanical pump valve (item 2).

10) Open the source isolation valve (item 1 ).

11). Open the vent valve (item 3 ).

\subsection{Safety Interlocks}

To protect the source region against arcs in the event of sudden, excessive pressure bursts ( $e_{.} g$. if a leak suddenly develops, or the instrument is vented with the source high voltage on), there are various interlocks: that automatically switch off critical voltages. Both the source high voltage and the filament power supply are interlocked to the ion gauge, i.e. the ion gauge must be on for either of these units to be on. The ion gauge is interlocked with circuit Reg. $1 P$, and anything drawing its power through that circuit automatically goes off with the ion gauge. The ion gauge turns itself off at about $10^{-3}$ torr, which is low enough to prevent a major cal amity.

The oil diffusion pump is interlocked with both its backing thermocouple gauge and the ionization gauge. The latter interlock can be bypassed at will; the former is adjustable on the thermocouple gauge meter with the set point needle. Experience should dictate a satisfactory setting for this need]e.

The multiplier high voltage supply is interlocked with the Varian VacIon power supply controlling the three pumps on the analyzer region; when 
the control goes off, so does the power supply. However, because of the sensitivity of the detector to high pressures and arcs, we strongly recommend turning off the voltage to it anytime an operation is being performed that could in any conceivable way damage it.

\subsection{Operation of the Analyzer Isolation Valve}

The analyzer 1solation valve is a Granville-Phillips $1.27 \mathrm{~cm}$ (0.5 in.) type Series 208 straight through valve. It is of all-metal construction and is capable of holding pressures below $10^{-8}$ torr on one side while the other is at atmosphere.

This valve seals by pressing a precision knife edge into a thin copper surface. It is therefore extremely important to onsure that this surface is not contaminated with hard or abrasive materials that would damage the sealing surfaces when the valve is closed. A torque wrench is provided and should always be used when closing the valve. The tag attached to the valve specifies the proper torque to be applied to achieve high-vacuum sealing. As the valve ages, somewhat higher torques will be required for proper closing. Reliable high vacuum sealing through many thousands of cycles will be obtained if the valve is kept clean and properly torqued when closed.

When opening the valve, wrench liius be used to overcome the closing torque. Once loose, the valve should then be hand-turned to the full open position. Full opening is achieved when a slight resistance to hand-turning is noticed, and the valve should not be forced past this position. The reader is referred to Granville-Phillips data sheet 208-1, 6/21/63, for complete construction details and information concerning baking of the valve. One word of caution: the screw in the top of the hand wheel should never be allowed to become loose. If loose, this screw can turn itself out of the sealing unit when the valve is being opened. This will allow the knife edge to fall onto the copper surface and will destroy the seal. The valve will then have to be :returned to the factory for repair. If this screw is observed to be loose (i.e. if it rotates independently of the valve handle), it can be tightened by first closing the valve using the recommended torque and then firmly tightening the screw with a screw driver. 


\subsection{Benzene Sample Reduction}

To run uranium or plutonium samples successfully as solutions or from wires, it is necessary to reduce them in the vacuum system. If this is not done, too much of the sample is lost as oxides, which are more volatile than the metal; the metal ion signal becomes erratic and frequently decays away before enough data can be collected.

This reduction is most conveniently performed during the pump down cycle. When the diffusion pump has evacuated the system to $<10^{-4}$ torr, the benzene leak valve (Granville-Phillips variable leak) is carefully opened until the pressure reads $2-7 \times 10^{-4}$ torr. Each filament in turn is heated to about $1400^{\circ}$ for $\mathrm{U}$ or $1200^{\circ}$ for $\mathrm{Pu}$ and held there 30 seconds. This accomplishes reduction of the sample. Samples loaded as resin beads do not need to be reduced in this fashion; the bead itself acts as the reducing agent.

The reservoir holds enough benzene to last several years during normal operation. When it needs replenishing, laboratory grade benzene is used to refill the reservoir. The fresh benzene must then be outgassed to rid it of entrapped oxygen. This is done by freezing the benzene with liquid nitrogen and pumping with the rough pump on the reservoir through the open leak valve until the benzene has melted. This should be done 2 or 3 times al together to ensure that all oxygen has been removed.

\subsection{Finding and Focusing the Ion Beam}

It is possible to get a beam through the instrument with the Mode switch on the Sweep Control panel in Local. Because the computer is not on line, the data do not accumulate from sweep to sweep this condition is thus useful only for rudimentary testing. To test mass spectrometer parameters, such as beam width or shape, it is necessary to activate the computer even though there is no intention of taking data. It is advisable to use the NBS standard to do pretiminary tuning operations at the start of each day. This precludes the loss of a real sample in the event of unforeseen difficulties. 
To initiate proceedings, enter. R MSRUN on the DEC writer (See Section 6.4 for a description of this program). After supplying the input data it requires, set the Subgroup Mode switch on the Sweep Control panel to Test and the. Sweep Mode switch to Linear. Note that the Subgroup Mode switch cannot be in Store; an error message appears on the DEC writer if it is.

Rotate the desired sample into position, open the source isolation valve (a vital step:), and turn on the source high voltage.

Bring the temperature up siowiy untī a few counts begin to register in the position of the most abundance ion expected-238 for U-or until you reach $1600-1700^{\circ} \mathrm{C}$. If the latter occurs, some parameter is probably badly out of tune, and the focus controls should be adjusted until the beam appears. Stop the voltage scan on top of the peak hy switching the sweep rate knob to the off position and monitor the count rate meter as you adjust the focus controls on the Source Divider panel for maximum intensity. As in all mass spectrometers, there is more art than science here, but experience breeds perfection. The focus controls are (See Figure 3.1):

1) Draw-out: adjusts potential difference between case and draw-out plates. Coarse and fine adjustment are avallable.

2) Focus: adjusts potential between the twn forus plates; the voltage on the two plates can be raised or lowered by simultaneously increasing or decreasing the two potentiometers. This adjustment moves the beam in the $Y$ direction, which is parallel to the floor and perpendicular to the beam. Coarse and fine adjustment is possible.

3) Z plates: acts in a manner similar to the focus plates except in the $Z$ direction (perpendicular to both flour and beam).

4) Magnets: these adjust the strength of the fields of the two magnets. It is best to adjust only. the rear magnet; it is only very rarely that the front magnet should need adjusting. Magnet adjustment takes slope out of the tops of the peaks; examples of good and bad peaks are shown in Figure 3.8. Coarse and fine adjustment are available. 

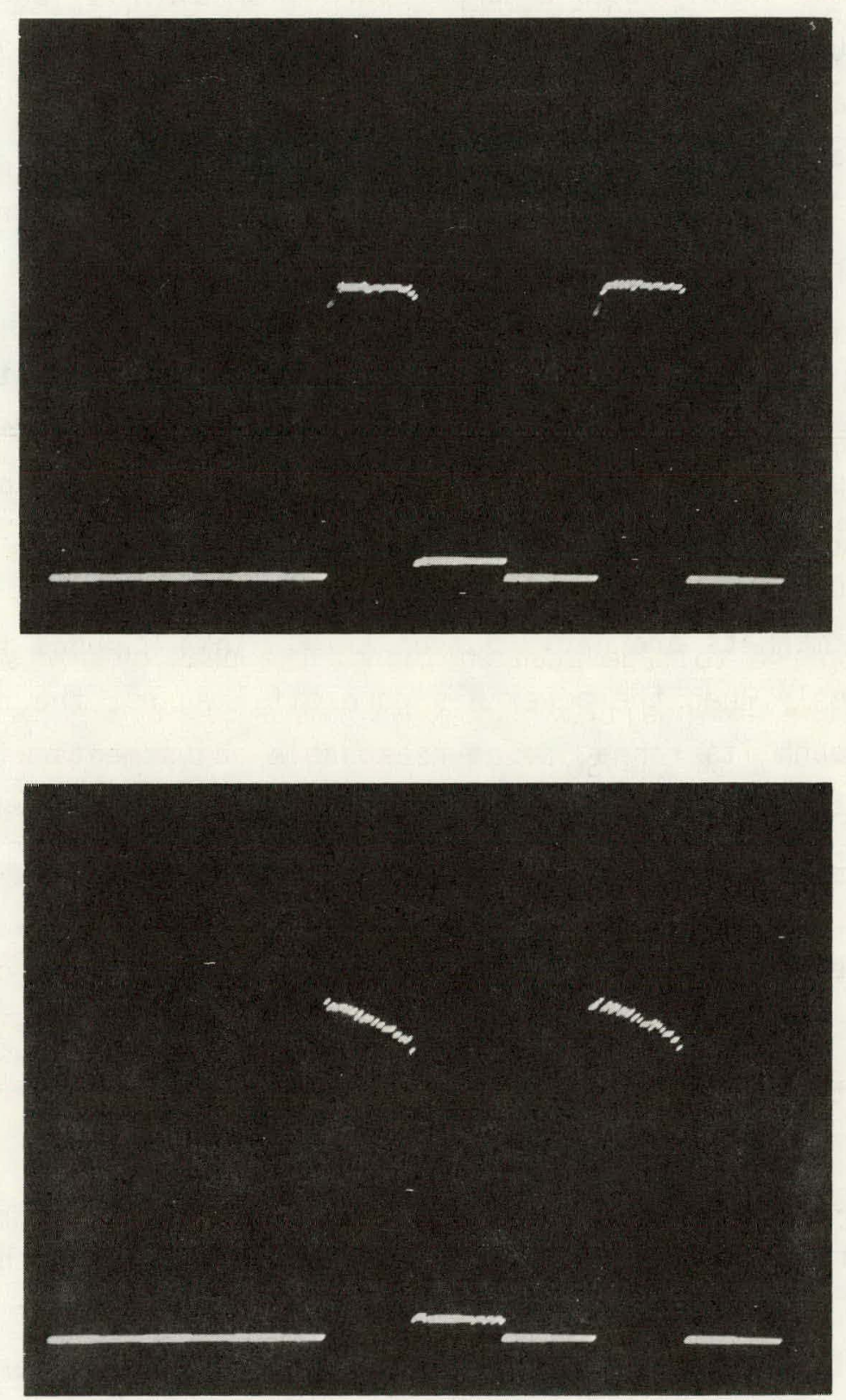

Fig. 3.8 Effect of magnet adjusting on peak shape. 
It is very likely that a temperature increase will be necessary to bring the count rate up to operating intensity $(100,000-300,000$ counts/ sec for normal samples). Once the count rate is reasonably stable, data collection can begin (Section 3.13).

In case no beam can be found, here is a check list arranged in approximate order or frequency:

1) You have forgotten to open the isolation valve.

2) You have forgotten to turn on the source high voltage.

3) You have forgotten to turn on the detector amplifier.

4) Some focusing parameter is badly detuned. Note the present positions of each potentiometer and investigale. A youd sequence to use is focus, $Z$, draw-out.

5) The magnets are badly out of trim. This happens fairly frequently when the power has gone off. Adjust the rear magnet through $i$ ts range, doing reasonable adjustments with the focus controls at each step. This process can be tedious and timeconsuming; opening the slits wide usually helps.

6) The multiplier voltage has gone off.

7) Some stage in the amplification chain has broken down. Call for electronics help.

Ihese steps should be undertaken while using the standard as the sample.

Once a beam has been found, the oscilloscope display can be cleared and the accumulation of counts started again by pressing the Restart Run button. The clear counts button clears all the counts but starts the scan at some arbitrary place rather than at channel 1 as the Restart Run button does.

The position of each individual subgroup should be checked for each sample. Because the entire spectrum is displayed continuously in the Subgroup-Store mode, it is usually a simple matter to make any necessary adjustments while in this mode. However, it is also possible to set the Sweep mode to Test and the Subgroup mode to Single Subgroup and have only one subgroup displayed while the appropriate potentiometer is adjusted to 
bring it to the correct voltage. The instrument is delivered with the first row of potentiometers set for $U$ at about 9170 volts and the second for $\mathrm{Pu}$ at 9050 volts.

\subsection{Taking Data}

Once 211 instrument parameters have been set as described in the previous section, it is time to take data. The Sweep Control panel is still under computer control from program MSRUN. To accumulate data:

1) Set the Sweep Rate switch to $2.0 \mathrm{msec} / \mathrm{channel}$. $0.5-50.0 \mathrm{msec} /$ channel are allowed data taking sweep rates, but we strongly recommend $2.0 \mathrm{msec} / \mathrm{channel}$ as the optimum compromise between speed (counting system live time is reduced at faster rates) and time required (sample decay is a problem at slower speeds). Fifteen or twenty minutes of data taking is sufficient for 10 runs.

2) Set the Subgroup Mode switch to SG (subgroup).

3) Set the Sweep Mode switch to Store.

Step 3 automatically initiates data taking, so it must be executed last. If for any reason you wish to reject a run, press the Restart Run button. This automatically clears the memory of current data and restarts the run. If it becomes desirable (usually because of rapid signal decay) to check the focus conditions during a run, move the Sweep Mode switch to Test and carry on as described in the previous section; once everything is optimized again, go through the 3 steps outlined above to initiate data accumulation again. The program interrogates the Restart Run and End Sample switches after each subgroup.

The End Sample switch should be pressed when enough data have been accumulated on the sample-usually 10 runs. The number of the current subgroup, sweep, and run are displayed on LED's in the upper portion of the Sweep Control panel, so that it is possible to know precisely where the data-taking process is at any given moment.

Gradual signal decay is very common and, with a little experience, can be compensated for by smal1 $\left(10-20^{\circ} \mathrm{C}\right)$ increases in filament temperature. Be sure to press the Restart Run button after increasing the temperature; 
it is not desirable to have data from different temperatures in the same run. Sloping peak tops are indicative of magnet imbalance and may be corrected by adjusting the second stage magnet control. If the source high voltage should drift, all subgroups will become misaligned with their peaks (See Figure 3.9 for examples of good and bad alignment). A small adjustment $(\sim 7 \mathrm{~V})$ of the source high voltage will correct this. If only one subgroup seems to be misaligned, correct it by adjusting the voltage of the appropriate subgroup potentiometer on the Sweep Control panel.

It is important that the operator be present during the entire datataking process so that any problems arising may be taken care of.

\subsection{Changing Samples}

When data collection for a given sample is finished, turn the filament current off. The wheel may now be rotated to bring the next sample into position; the source high voltage can remain on. Try to center the filament with respect to the case plate slit as well as possible. Marked losses of transmission will otherwise result. If contact is not made and no current will flow through the filament, a small rotation will usually correct matters. If no current ever flows, the filament is probably burned out or a spot weld has broken.

\subsection{Short Term Shut-Down}

If the instrument is to be unattended for more than a few minutes, such as at lunch time, it is advisable to turn off the source high voltage. This reduces the chances of some sight-seer being shocked and precludes the possibility of an unobserved arc. It is good practice to close the isolation valve so that if something disastrous occurs in the source vacuum region the multiplier will be unaffected. Other electronic equipment may be left on. 

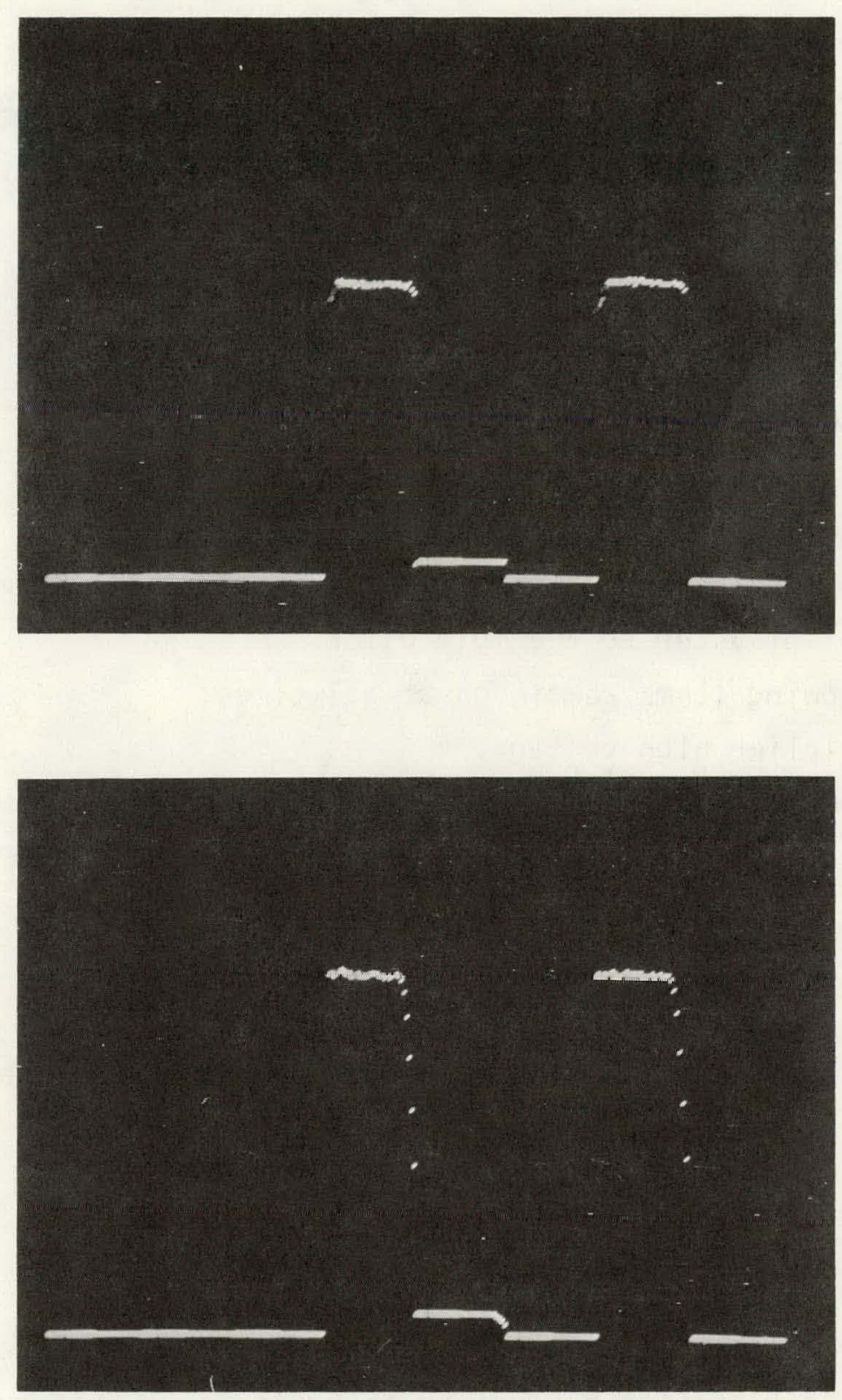

Fig. 3.9 Effect of voltage drift on peak positions in subgroups. 


\subsection{Long Term Shut-Down}

When shutting down for overnight or longer, the following items should be turned off (sequence is unimportant):

1) Source high voltage supply.

2) Filament power supply.

3) Computer.

4) Subgrouper.

5) Sweep amplifier.

6) Count rate meter.

7) Detection system amplifier.

In addition, the isolation valve should be closed to minimize the possibility of disaster to the multiplier.

The following items remain on at all times:

1) Multiplier high voltage.

2) Magnets.

3) Ion pumps.

\subsection{If the Power Fails}

A sudden power outage is a nuisance, but should not cause major problems. Here is a list of things to do when this happens:

1) Turn off multiplier high voltage.

2) Close isolation valve.

3) Wait for power to come back on.

When power returns, the analyzer ion pumps should come on automatical1y. The alialyzer section has vacuum integrity such that even if the power were to rella in off for several hours, the pressure should not come up past $10^{-6}$ torr. 


\section{CHAPTER 4. MAINTENANCE OF THE VACUUM SYSTEM AND DETECTOR}

\subsection{Vacion Pumps}

Since an ion pump works by gettering ions with sputtered titanium, $i$ ts pumping elements will have a finite life. Elements on the $1401 / \mathrm{sec}$ pump on the source region should last several years at the average pressures maintained. When pumping becomes sluggisti, a bakeout of several hours will frequently restore the pumping speed. Because of the heavy use to which the pump is subjected and the necessity of $i$ ts. continued operation, we recommend that one set of titanium replacement elements be kept on hand at all times. Otherwise, only routine precautions should be necessary. The lower the pressure when the gate valve is opened, the longer its life will be, so it is desirable to let the oil diffusion pump evacuate the system to as low a pressure as practicable.

The Vacion pumps on the analyzer section, since they are exposed to. such a small gas load, should last for many years without needing attention.

\subsection{Diffusion Pump}

A Varian/NRC model M-2 oil diffusion pump is used to assist in pumping the instrument down from atmosphere and to maintain a constant benzene pressure during sample reduction. An instruction manual is included; we only caution you to be sure that the pump is valved off when the spectrometer is vented. Power to the pump may be turned off between uses. Since the pump is used relatively little in comparison to continuous operation, a charge of pump oil should last for years. The usual symptoms, principally sluggishness, apply, and a new charge of oil will have to be introduced periodically. The pump is supplied with polyphenyl ether (Convalex 10) pump o.il; any reasonable substitute would be acceptable. The pump is topped by a Varian/NRC M-2 water-cooled baffle to reduce back streaming. 


\subsection{Cleaning the Source Can}

Occasionaliy an accident, such as back-streaming of pump oil, may occur which requires cleaning of the source can. Try all conceivable in situ cleaning methods before considering removal of the can. The can is made of 304L stainless steel, and this will tolerate most solvents except $\mathrm{HCl}$. Either benzene or 1-1 $\mathrm{HNO}_{3}$ may be swabbed around the inside of the can without fear of chemical attack. Be careful not to introduce solvent into the tube leading to the isolation valve, where the copper seat is vulnerable (see Section 3.9), or allow any to run down the throat to the gate valve. Be careful around the high voltage feed-throughs.

No other part of the vacuum system should ever need cleaning; pieces are made of 304L stainless steel except the analyzer tubes, which are gold plated OFHC copper wave guide.

\subsection{Changing Multipliers}

A multiplier used in pulse counting mode has a much shorter life expectancy than one used as a current integrator. Our experience at ORNL has found lifetimes ranging from zero to 5 years. An occasional multiplier is defective to start with; two dynodes can be shorted together, or the unit may have lost its vacuum seal, which usually results in no gain. Other multipliers have too little gain to be usable at a voltage low enough to meet background noise requirements:. Still others are too noisy to be used at any voltage regardless of gain. A11 these reasons can lead to very short multiplier lifetimes, and about one. RCA type 6810 in four will have such a problem. Once an acceptable multiplier has been found, it will usually last a year or more.

There are many symptoms of a dying multiplier. Frequently a previously stable detector will lose gain and require successive increases in voltage to reach its plateau (see Section 2.1). : "Eventually"a voltäge will be reached at which the noise becomes too great for continued operation.

Diagnosing the above fatal illness is relatively simple and straightforward because the symptoms are clear-cut. Other fatal ilinesses display 
other, more subtle, symptoms: Inability to obtain reproducibility in the daily standard can mean that a new multiplier is needed. Or trouble may evince itself as a gradual increase in standard deviations of routine samples. In either of these cases, or, indeed any time a defective multiplier is suspected, try changing sources first (Section 3.1). This will frequently solve the problem. Try all conceivable electronic checks unless the evidence is completely unambiguous. It is tragic to change a multiplier and then still have the same problem as before. So be as certain as possible that the multiplier is at fault before changing i.t.

The first step in the installation of a multiplier is to solder it to its mounting flange, three of which are provided. The lip of the multiplier mounting flange should be gently filed to clean it, unless it is gold plated, and a bead of solder run around it. Be sure to use solid core solder with acid flux; rosin core solder is not to be used in high vacuum applications. Be extremely careful in all these soldering operations not to break the glass envelope of the multiplier.

Run a bead of solder around the mating surface of the mounting flange, and mate the multiplier to it. Inspect the solder joint carefully and touch up any suspect points.

A micro torch may be used for soldering, and is recommended when heating the mounting flange initially. Because of the danger of cracking the glass multiplier housing with a flame, it is recommended that the later stages of the operation be done with a soldering iron. The glass through which the electrical leads pass is lead glass and is extremely sensitive to heat, force, etc $c_{0}$; in fact, treat it as though it were dried butterfiy. wings.

Once a satisfactory solder joint is made, it should be allowed to cool and should then be thoroughly cleaned with distilled water and alcohol to remove all traces of solder flux. The unit may be leak tested if desired. However, ORNL experience has been that tightening the flange frequently causes smali leaks to appear in the solder joint, and we prefer to be extremely careful in. making the solder joint and forego leak testing.

It is desirable to mark the four leads that must be tied together at this time. The two end wires are usually bent by RCA for guidance. They 
are numbered 1 to 4 in Figure 4-1a. It is good practice to have two multipliers soldered onto their flanges: at all times.

When multiplier change time comes (as it inevitably will), some precautions must be observed before venting the system. Two support braces must be attached to the multiplier mount to protect the bellows from mechanical strain generated when removing and replacing the multiplier mounting flange. The multiplier high voltage, analyzer ion pump power and pulse amplifiers must be turned off. The pulse amplifier is deactivated by turning off the A.C. power to the NIM-bin pane 1. When this is done, the venting instructions in Section 3.8 should be followed, with the isolation valve open and the ion source either loosened or removed from the spectrometer. The multiplier flange may now be removed. The multiplier may now be withdrawn from its chamber. The glass sleeve that insulates the multiplier from the concentric magnetic shièld will usually come out with the multiplier and should be kept clean and handled with care.

The glass housing of the new multiplier must be broken off; a shallow scratch around its base helps make a smooth break. Nip the tip off the lead glass evacuation tubulation to let the multiplier up to air. Break the glass housing with a pair of wire cutters, being careful to remove all shards around the base. Snip off the Cs reservoir and Sb-Mn activator beads.

Remove all wires shown in Figure 4-1b. In addition, an old multiplier from ORNL is supplied to be used as a model. Put a copper gasket on the flange if you haven't already done so. Silp the multiplier into the glass shield and install it in the instrument; be sure to keep the correct orientation of the first dynode. The length of the dynode should be perpendicular to the floor to ensure uniformity of response along the length of the beam. Tighten the bolts and carefully seal the projecting lead glass tubulation with a cool flame. Be sure the projection is short enough to allow installation of the preamplifier.

Be very careful of the lead glass! Once the glass has cooled, open the valve to the rough pump. You can get a head start on pumping by closing the isolation valve and roughing out the source region while you are installing the multiplier. Be sure the source is loosened or you will be pumping the 

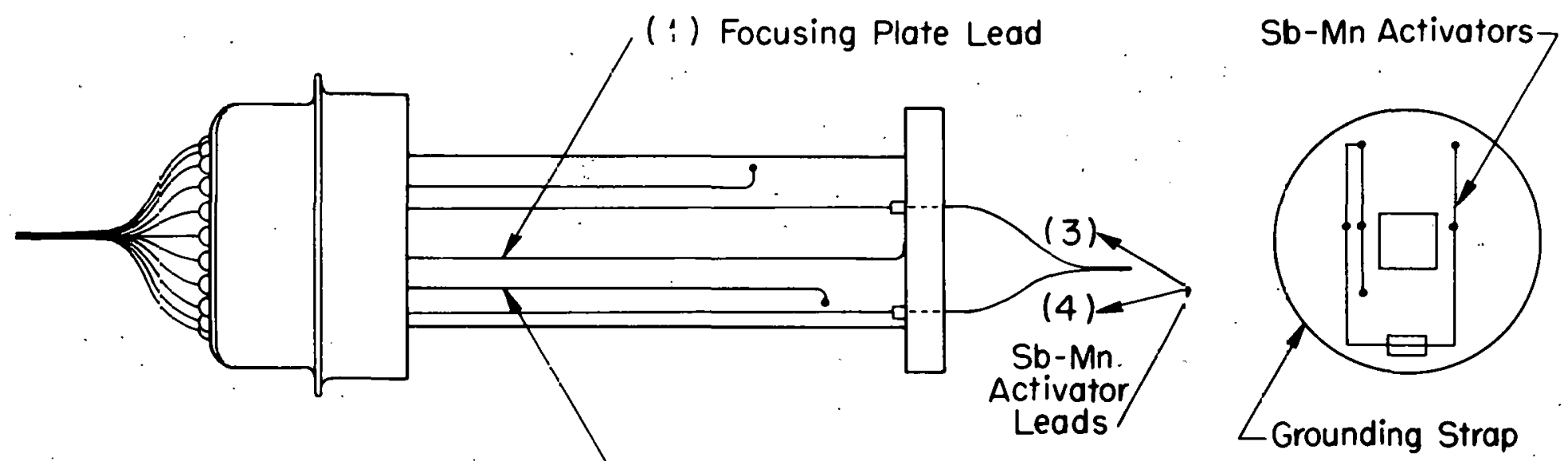

(2) Ion Regeneration Shield Lead

b

Fig. 4.1 Preparation of a multiplier for installation.

a. Four wires to be joined.

b. Wires to be removed. 
entire analyzer section through the exit slit of the source; this takes a very long time indeed.

Once the glass envelope of the multiplier has been broken, you should move as quickly as you can without jeopardizing the multiplier with undue panic. It should take 5-10 minutes between breaking the envelope and starting to pump.

Tightening the multiplier flange unevenly frequently causes small leaks to form in the multiplier solder joint. These can almost always be closed with Vac Seal (supplied), and almost never by trying to resolder while the multiplier is under vacuum. So, even though it is not esthetically attractive, we strongly recommend the use of Vac Seal in this application. Vac Seal has a vapor pressure low enough to have no effect on the ultimate vacuum, and it is surprisingly effective. It can be baked to $200^{\circ} \mathrm{C}$.

Ul timate pressure in the analyzer region should be essentially too low to measure with the pump source supply meter (below $210^{-10}$ torr).

When you are convinced that the multiplier seal does not leak, connect the multiplier leads to the preamplifier, being sure to maintain the correct orientation of the leads. Failure to do so will prevent the multiplier from working.

There is little point in trying to analyze samples until the multiplier has had a chance to stabilize. It is recommended that it be left at $3 \mathrm{kV}$ overnight; it will usually be stabilized after this time.

Multiplier calibration is covered in Section 2.1.

\subsection{Leak Hunliny}

An unfortunate fact of life is that vacuum systems occasionally develop leaks. This section will make no attempt to teach leak hunting. and will only indicate some potential trouble spots. A helium leak detector is essential since leaks large enough to be found by other techniques are rare.

The soft solder seal around the multiplier is the most common source of leaks. They are usually readily repaired with Vac Seal (Section 4.4). 
Over the course of years of service we have had high voltage feedthroughs into the source can develop leaks. Repetitive tightening of the screws for the source high voltage connections eventually causes the feedthrough wall to wear through.' These leaks can be fixed by silver-soldering the end of the feed-through in situ.

The viton 0-rings that seal the glass plate to the source can tend to flatten with age and need to be replaced periodically. ( 2 years).

Leaks other than those mentioned above are extremely rare. You are at the mercy. of the spectrometer gods and will have to struggle through any such incidents when the time comes. 


\section{CHAPTER 5。 ELECTRONICS}

\subsection{Overview}

The electronics used in this mass spectrometer can be divided into two general classes:

Mass Spectrometer Electronics. Equipment to generate, separate, measure, and controi ions within the mass spectrometer itself.

Auxiliary Electronic3. Devices required to create and iieasure the vacuum in various parts of the system.

The electronics involved with the vacuum system are commercial equipment, and their use is described in other parts of this manual. The only electrical connection between the two systems is in the protection circuits. If the pressure in the ion source chamber rises above a pre-set pressure (measured with the ion gauge), the 115-volt power to the filament and the source high voltage supplies is cut off. Likewise, if the collector chamber pressure rises above the pre-set limit (measured by its Vacion pump), the line voltage to the multiplier power supply is shut off. The protection systems must be manually reset before the mass spectrometer can be operated again.

\subsection{Mass Spectrometer Electronics}

Figure 5.1 is a block diagram of the electronics of the mass spectrometer, which can be divided into 4 categories:

1) Source

2) Magnets

3) Collector

4) Control, data processing, and computer.

\subsubsection{Source Electronics}

The source electronics consist of a filament-heating supply and a voltage source to accelerate ions into the analyzer region. The filament power supply is used to heat the sample filament to a temperature high 


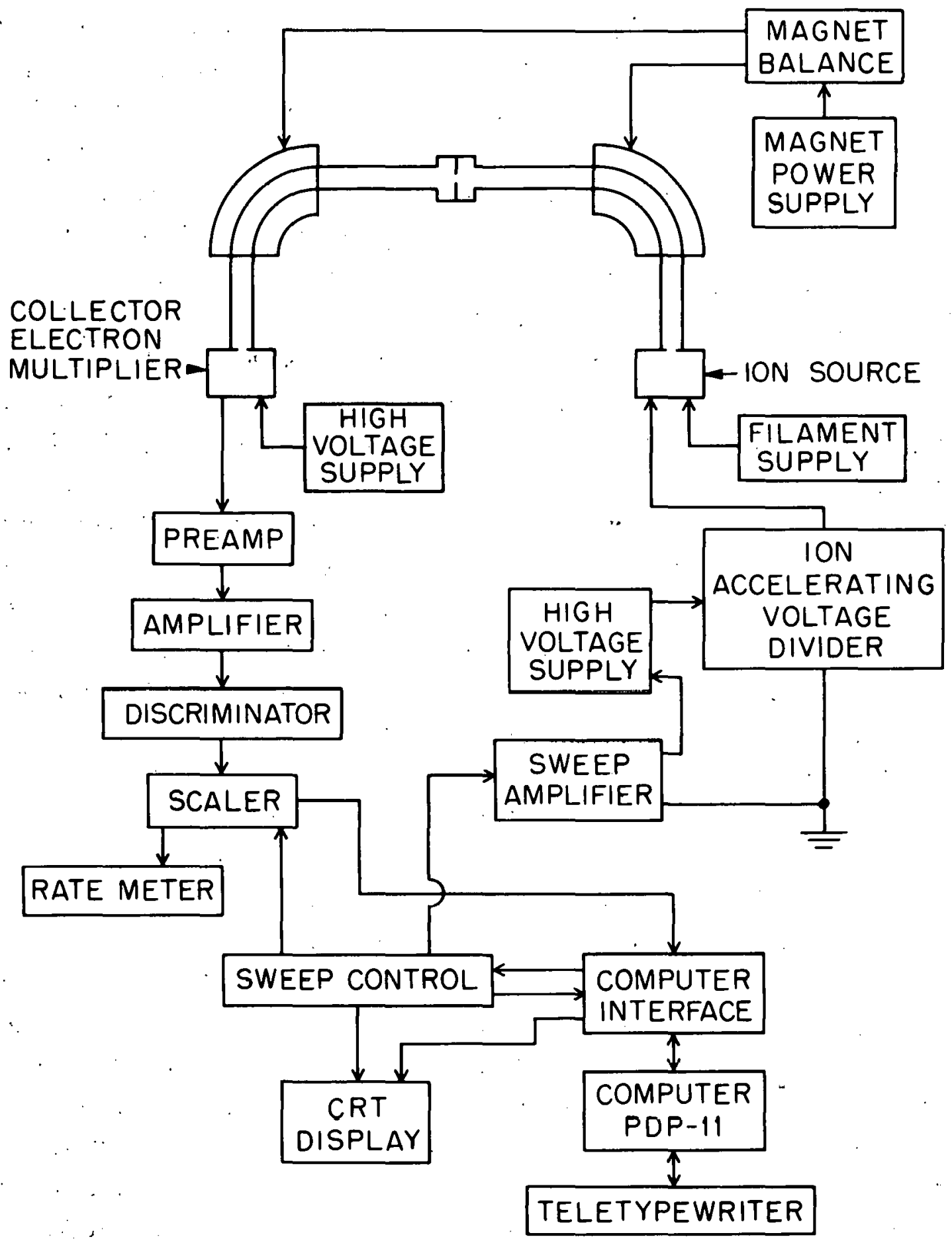

Fig. 5.1 Block diagram of electronics. 
enough to produce ions. This supply creates a manually control led current of 0 to 10 amperes $d_{0} c_{0}$ with a regulation better than $1 \%$. Control is attained by adjusting a 10-turn potentiometer. Emission of uranium ions usually occurs between 6 and 8 amperes and plutonium ions at 5 to 6 amperes. A11 parts of the filament circuit except for the 115-volt input are insulated from ground to withstand the $10 \mathrm{kV}$ present at the ion source case plate to which the filament is electrically connected. Care must be taken to avoid personal injury when examining this part of the system. In. normal operation, all high voltages are behind metal or plastic shields.

Ion accelerating voltages are supplied to the source from a divider pane 1. The filament and case plate operate at the potential provided by the sum of the outputs of the high voltage power supply and the sweep amplifier. Potentials to the Draw Out, Focus 1, Focus 2, Z1, and Z2 electrodes are some fraction of the case plate voltage and are adjustable by front panel controls for best ion beam focus. Mass range and sweep rate are determined by settings on the sweep amplifier and sweep control panels. During normal operation an analog voltage obtained from the computer is amplified by the sweep amplifier and added stepwise to the ion accelerating vol tage to produce a mass scan. The gain of the sweep amplifier is manually adjustable from 7 to 60 via the front panel controls.

Ion beam focusing can be performed wi thout use of the computer. In this case, the sweep signal is obtained from a local oscillator. These features are described in more detai 1 in later paragraphs.

\subsubsection{Magnet Electronics}

The magnetic fields for the analyzer are generated by two identical electromagnets with a maximum attainable field of approximately 8000 gauss. Power for the two magnets is derived from one voltage-regulated power supply which is manually adjustable from 0 to 30 volts. The magnet bal ance control (see figure 1.4) allows the operator to adjust the relative currents to each of the magnets for ion beam focusing purposes. The maximum relative current adjustment between the two magnets is approximately $0.3 \%$. 


\subsubsection{Collector Electronics}

Ions that pass through the final collector slit impinge directly on the first dynode of a 14-stage electron multiplier (RCA type 6810). Multiplier dynode voltages are provided by a resistor string, which in turn is powered by a 0 -to-6000 volt power supply. Normal operating voltage is about 3000 volts.

Ion current signals from the mass spectrometer are amplified by the multiplier, preamplifier, and amplifier as individual pulses, not as an analog current. The two amplifiers (ARL model 104450) are high frequency pulse amplifiers with a voltage gain of 30 and a combined output of approximately 0.5 volts. This amplified pulse signal is applied to the input of the discriminator (ORTEC model 436). The discriminator accepts only input pulses of an amplitude greater than a pre-set threshold value and then generates a standard output pulse on a one-for-one basis. This allows the system to eliminate small background noise pulses which are always present in any electron multiplier. The standardized signal pulses are then counted in the computer-controlled scaler. Adjustment of the multiplier high-voltage is described in other parts of this manual.

A rate meter is also connected to the scaler to give the operator an indication of the instantaneous ion current without the signal having to pass through the computer.

\subsubsection{Sweep Control Electronics}

The remainder of the mass spectrometer electronics includes a PDP-11 computer, its interface, a sweep control panel, and a cathode ray oscilloscope display. Figures 5.2 and 5.3 are photographs of the Sweep Control and Oscilloscope Display panels. While taking data, the computer determines the mass which is being measured, receives the corresponding ion current from the collector system, and displays on the oscilloscope the contents of the data memory. At the end of a run the accumulated mass spectrum is transferred to the disk for further processing at a later time. It is through the Sweep Control panel that the operator has live time control of the sweep parameters of the mass spectrometer. The Sweep Control panel has 4 different modes for sweep operation: 


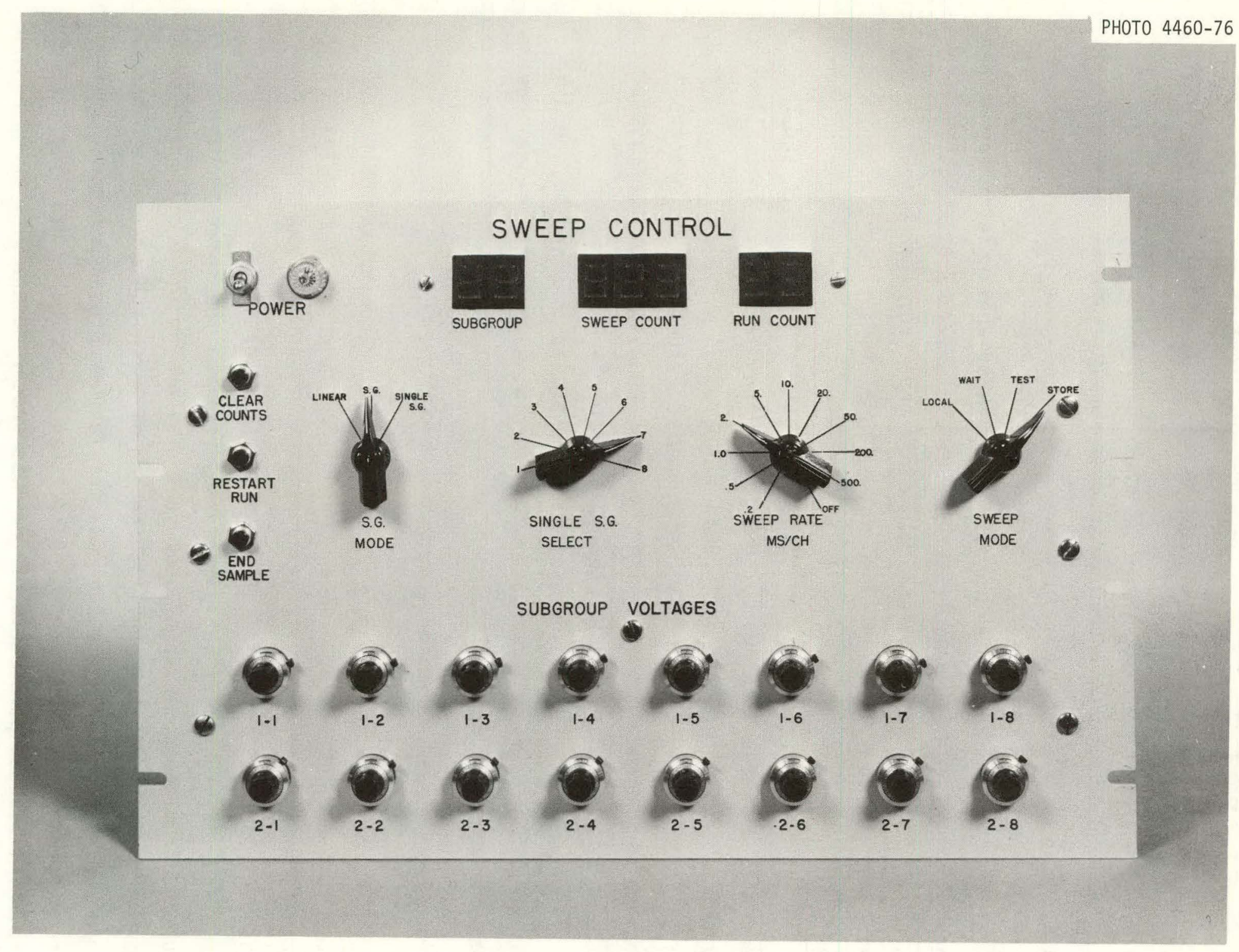

Fig. 5.2 Sweep control panel. 


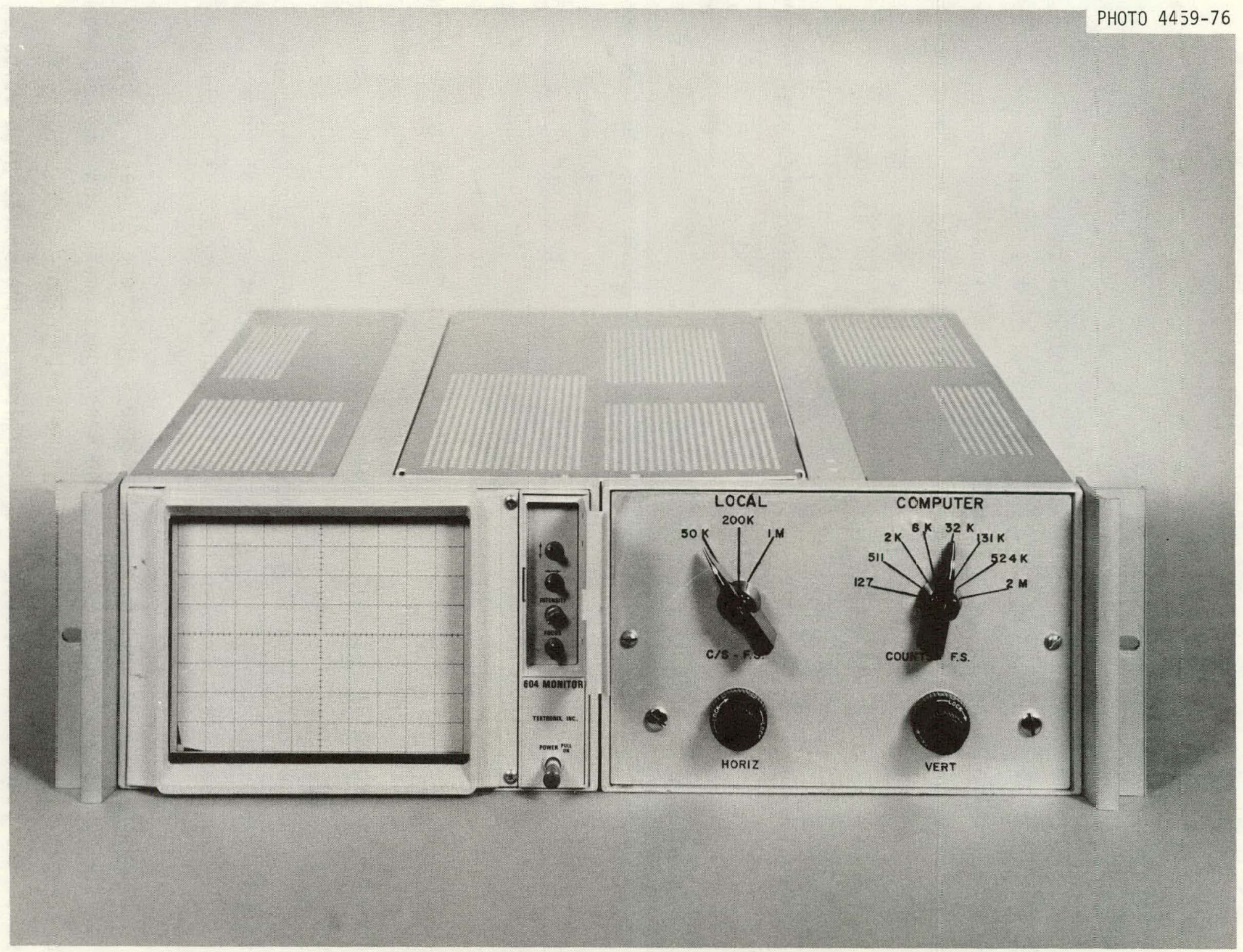

Fig. 5.3 Oscilloscope display panel. 


\section{1) Local}

2) Test

3) Wait

4) Store

With the Sweep Mode switch in Local, the mass spectrometer can be operated without the use of the computer. An internal sawtooth generator of approximately 50 Hertz provides a sweep signal to the Sweep Amplifier and the horizontal axis of the oscilloscope. An analog signal proportional to the instantaneous ion current received at the multiplier is displayed on the vertical axis of the oscilloscope. Thus, an instantaneous graph of the mass spectrum is displayed. Since storage of information is not possible in this mode and no accumulation of data is possible, the display drops to zero when the ion beam is turned off. This mode is useful when preliminary work is being carried out to detect the presence of a particular sample without the use of the computer. Preliminary focusing and alignment studies can also be made in this mode.

With the Sweep Mode switch in the Test position, the mass spectrometer is under computer control. Subgroup or linear sweeping of the mass spectrum is selected by the Subgroup (S.G.) Mode switch. The positions of the various subgroups in the mass spectrum are adjusted by the corresponding front panel potentiometers. Each new ion current count is transferred into the computer at the completion of the channel period determined by the Sweep Rate switch. The number being transferred is added to the number already stored in the computer for that particular channel. This new sum is then displayed on the oscilloscope. The width of the display is fixed at $8 \mathrm{~cm}$. Three digital readouts (subgroup number, sweep count, and run count) are also provided on the panel. They display the current value of these variables as they are stored in the computer and are automatically changed as sweeping progresses.

The Subgroup Mode switch determines the scan scheme (linear, subgroup or single subgroup). In Linear Scan the mass spectrometer and the oscilloscope repetitively sweep through 256 channels in uniform succession. The mass at the start of the spectrum is determined by the source high voltage and the position of subgroup potentiometer 1-1. The range of the spectrum 
is determined by the gain of the Sweep Amplifier. The control panel remains continuously in subgroup 1-1. The sweep counter increments after each sweep up to the value entered previously into the computer through program MSRUN. When this point is reached, the sweep counter is set to zero. The run counter remains unchanged, and the individua? channel data continue to accumulate without being zeroed. In Test Mode, no data are transferred to the computer disk, and the data memory continues to collect and add new data until terminated by the operator. Pressing the Clear Data switch zeroes the data memory as long as it is depressed. Pressing the Restart Run switch resets the run counter to 1 and clears the data memory. Pressing the End Sample switch has no effect in Test Mode. The Subgroup Mode and Sweep Rate switches may be changed at will in Test Mode without affecting the computer.

If the Subgroup Mode switch is moved to the subgroup position, the computer and mass spectrometer are put in subgroup mode. This means that the only parts of the mass spectrum swept are those determined by the computer and the subgroup voltage potentiometers. Thirty-two channels comprise one subgroup. The horizontal location for the various subgroup bands on the oscilloscope accurately display their position relative to the rest of the spectrum. This is very useful in determining the correct adjustment for each subgroup voltage potentiometer. Each subgroup is scanned a pre-set (computer controlled) number of times before passing on to the next subgroup. This value may be programmed from 0 to 32 .

If the switch is muved to the single subgroup position, the subgroup selected by the Single S.G. Select switch is swept repetitively. This position is most useful when it is necessary to change subgroup settings.

When the Sweep Mode switch is moved from the Test to Wait, new data are prevented from entering the computer, and the information stored in the data memory is continuously displayed on the oscilloscope. This provides a temporary display of data for visual analysis. After switching back to Test and pressing the Restart Run switch, the system returns to Test Mode.

When the Sweep Mode switch is placed in the Store position, the computer system will accumulate data and transfer it to the disk after the 
prescribed number of cycles. The computer program and the control panel must be in the same mode. Any change of the Subgroup Mode or Sweep Rate switches will cause the current run to be terminated and an error message to appear on the DEC writer. It is thus necessary to have the $S$. G. Mode and Sweep Rate switches in their correct data-taking positions before moving the Sweep Mode switch to Store. Re-entry into the Store Mode is achieved by correcting the error and pressing Return. The display in Store mode is a continuous indication of the information in the data array of the computer, and no space is present between the subgroups. The run may be restarted at any time by pressing Restart Run switch. The sample is terminated by pressing the End Sample switch. Further description of operation of these controls is given in Chapters 3 and 6 .

The prints and circuit diagrams supplied with the instrument are intended to be used for maintenance purposes only. Copies should not be made for distribution to people affiliated with organizations other than the International Atomic Energy Agency. 
CHAPTER 6。 COMPUTER PROGRAMS

\subsection{Description of the Computer}

The computer supplied wi.th the mass spectrometer is a Digital Equipment Corporation P.DP-11E10 with a 16K core and 1.2 million word disk. It is used as a data accumulator and processor; but not as an operator of the mass spectrometer., The programs for the computer may be broken into three groups :

1. Program to accumulate data, much of which is written in assembly language.

2.:. Program to process the data, all of which is in FORTRAN.

3. Auxiliary programs in FORTRAN.

\subsection{Disk Files}

Operation of the programs requires establishing several files on the disk which are needed either to store long-term constants or to store data associated with each sample. DEC FORTRAN requires that each file be initialized to its maximum size. This can be done either through PIP or through the appropriate FORTRAN program. The files, their functions, and how they are initialized are described below.

\section{2 .1}

CHDATA stores channel data for each individual sample. The capacity of the file is twenty samples of nineteen 256-channel runs. Each run is a record so as to be individually addressable. The size of the file is thus (20 samples $\times 19$ runs) $\times(256$ channe $1 \mathrm{~s} \times 2$ words/channel) or 380 records of 512 words each. The channel data must be stored as real words because the maximum integer allowed in the PDP-1.1E10 $(32,757)$ is not large enough to include all data. The file is initialized in program MSDAT; its operation is entirely automatic with no outside interference required.

\section{2 .2}

MSSAM. This file contains run information for each sample. There is room for data for 20 samples, each of which constitutes a single record. 
Record 2.1 contains the number of samples in the file, and wi.11 usually be 20. The file consists of 21 records of 60 words each; the sequence of the data in each file is: Index indicating whether sample data have been processed or not . (0 for no, 1 for yes); primary index (see section 6.4), sample identification, identification of unspiked sample (for spiked $\mathrm{Pu}$ sample only), title, sweep rate, sweep factors, masses, number of runs, number of cycles, spike size, comments, date.

This file is initialized in MSUAT, and its operatiun should be automatic. CHDATA and MSSAM are updated each time program MSRUN is executed.

\section{2 .3}

VCTSF. This flle contains live dead time and bias correction per mass in record 11. In each of the first 10 files, it contains (with the record number corresponding to the primary index) 8 sweep factors and masses, each corresponding to the given subgroup in the data taking scheme, a 0 for $U$ or 1 for $\mathrm{Pu}$, and the number of cycles this type of sample normally requires. VCTSF can readily be altered through program FILST. The file size is 11 records of 18 words each.

\section{2 .4}

SPISO. This file consists of 2 records containing the isotopic composition in atom fraction of the $U$ and Pu spikes. It thus has 2 records of 10 words each. It is readily al tered thruugli program FILST.

Neither of the above files requires attention unless changes are required.

\section{2 .5}

MSBKP. This is a bookkeeping file for MSOUT. It contains only sample identifications of those samples whose processed data are stored. in MSOUT. The maximum number of samples that can be stored is 100. The 101st record. contains the current number of samples. stored, and the file consists of lul records of 4 words each. It can be initialized through program MSREP.

\section{2 .6}

MSOUT. This file contains the results for up to 100 samples. These results are the 10 atom ratios and their standard deviations calculated in the data processing program (MS). Samples with a primary index of 3 (NBS 500 's) are not stored in this file. The file consists of 100 records of 40 words each and is initialized in program MSREP. 


\subsection{Overview of the Programs}

Before describing the programs in detail, it is desirable to present an overali. perspective of the basic philosophy behind them so the reader does not unnecessarily get bogged down in detail.

During operation of the mass spectrometer, when data are actually being accumulated, program MSRUN is executed. Various requests for information are filled by the operator, and once data taking has started, the program should proceed automaticality until interrupted by the operator. MSRUN is described in detail in the next section.

It is expected that, in normal operation, a full wheel of samples wi 11 be run and their data stored on the disk before any data processing is done. There is room for 20 samples of run data (see Sections 6.2.1 and. 6.2.2) before data processing becomes mandatory-dataifrom previous samples will be lost if one tries to store more than 20 samples. When ready to process data, program MS, which consists of several subroutines and a main Tine program stored in overlay mode, is executed. After telling the computer which samples are to be processed, the program processes the data without operator intervention; the results are stored on the disk (see Sections 6.2 .5 and 6.2.6). There is room for 100 samples in these output files, and it is up to mass spectrometric personnel to dump them periodically.

This philosophy allows the raw data from a given sample or samples to be retained on the disk until they are no longer needed; e.go., if it is necessary to recalibrate the instrument, data from several previous samples can be retained: and recalculated using the new instrument parameters. In addition, long term storage is always possible on cassette tape.

Sample results, should be retained in the output files only until a final report is written by program MSREP unless there is some compelling reason to keep them longer.

\subsection{Program MSRUN - Data Accumulation}

This program is the one under whose control data are accumulated. Upon entering $R$ MSRUN on the DEC writer, the date appears, followed by a 
string of questions that the operator must answer. First to be entered is the sequence number. Normally this should be. 1 (first sample of the day); it is incremented automatically as successive samples are run. Once the sequence number is entered, a list of the empty disk file numbers appears on the DEC writer, and the operator must enter the number of the file where he wants the data for the current sample to be stored. In practice, the disk files listed are not usually empty, but contain data for samples that have already been processed and whose continued presence in the disk riles as raw data are not usualiy necessary. If the data for one sample or group of samples are to be saved, the operator must know which disk files the data are stored in and enter the starting file number accordingly. The files (see Sections 6.2.1 and 6.2.2) have a capacity of 20 samples. If an entire sample wheel of six samples is run without leaving MSRUN (as should frequently be the case), the file number is automatically incremented after each sample: i.e., if the starting file were entered as 12 , the data for the samples would be stored in files 12-17. If 17 were entered as the starting file, the data for the six samples would be stored in files 17-20 and $1-2$.

The next input required is the sample log number ( 6 characters). Here should be entered an unequivocal identification for the sample, for this is the name under which it will be stored. We suggest that a mass spectroirietry laboratory log code be used.

Sample name is next; this can be anything you desire (up to 20 charac.ters) to describe the sample.

The sample type code is next. This is the primary index referred to previousiy. It is mandatory to enter the correct number here because it is used to determine which branches the program takes during the reduction of the data. The index is coded as follows:

\begin{tabular}{|c|c|}
\hline Index & Sample Type \\
\hline 1 & Normal U \\
\hline 2 & Spiked U \\
\hline 3 & NBS 500 \\
\hline 4 & Normal Pu \\
\hline 5 & Spiked Pu \\
\hline
\end{tabular}




$\begin{array}{ccc}\frac{\text { Index }}{6}: & & \text { Sample Type } \\ 7 & \text { Something else } \\ 8 & \text { Future expansion } \\ 9 & & \text { " }\end{array}$

Linear.scan

The index defines which subgroup scheme is read from file VCTSF (Section 6.2.3). These are written out on the DEC writer, followed by the question "Modify code?" Any response but "N" (for no or nein) or "Return" results in the program entering a correction loop that allows different sweep factors and masses to be entered. In each case, pressing the Return key is equivalent to making no change. At the end of the correction loop it is possibie to correct the number of cycles to be taken by entering the number desired. Again, pressing Return is equivalent to making no change. This is followed by the question, "Are the parameters correct?" Pressing the Return key is equivalent to answering "yes". and proceeding with the program. " $N$ " cycles the program back, and the questions are gone through again.

During data taking, the program interrogates various switches on the Sweep Control panel. Once data taking has started, these must not be touched unless you wish to restart a run or check the beam focus (see Sections 3.12 and 3:13). When the End of Sample button is pressed, data taking immediately :stops, and the number of runs stored on the disk is written out. An entry for comments is called for (20 characters). We suggest entering the temperature range here; this is occasionally useful in case of future: trouble. . The program is automatically. terminated after 19 runs have been collected.

After entering the comments, the program either cycles back to start a new sample or returns control to the keyboard monitor if no more samples are to be run.

\section{6:5. Program MS - Data Processing}

Program MS actually consists of a main line program (MSCAL) and seven 
subroutines (SUBGR, CALC, CAL2, CAL3, CAL4, CAL5, and CAL6). These together are too big for the 16K of core in the P.DP-11 and are thus stored in overlay mode. In addition, MSCAL must be compiled with the $\mathrm{N}$ switch option. DEC's default device number is 6 , and each individual file counts as an input/output device, as well as the disk, DEC writer, etc. These programs call for more than 6 devices, and the $N$ switch option allows up to 15 ( 17 octal) devices to be used. Thus, to compile MSCAL, the following command sequence is used:

-R FORTRA

*MSCAL, TT: = MSCAL/L/N: 17

The commands to the linker are:

. R LINK

*MS $=$ MSCAL, LIB/F/C

*SUBGR/0:1/C

*CALC/0:1/C

*CA[2/0:]/C

*CAL3/0:1/C

*CAL4/0:1/C

*CAL5/0:1/C

*CAL6/0: 1

Program MS automatically calculates the isotopic compositions of all samples; in addition, ratios appropriate to the given sample type (as indicated by its primary index) are also calculated. If a sample with an index of 6 (something other than $U$ or $\mathrm{Pu}$ ) is being calculated, input is required to tell the program just what calculations are required. In all other cases, the calculation of the samples proceeds without operator interference. If all previously unprocessed samples are to be calculated, no input file from the operator is required; if samples previously processed are to be calculated, he must enter the appropriate file numbers. Questions to be answered and console switch options available should be selfexplanatory. A detailed description of the statistical treatment of the data is given in the next section. 
If for any reason i.t is desired to take data in linear mode, the proper index to. enter is 10 . In program MS, there are two modes of operation available during data reduction: laborious identification of peak width and starting channels of each peak from a listing of all individual channels, and using a cursor in conjunction with oscilloscope display to select starting channels-peak widths must still be entered from the keyboard. Raising switch 6 on the PDP-11 console branches the program to the cursor subroutine. This causes each run to be successively displayed on the oscilloscope. The cursor scan is controlled by the Sweep Rate switch. At $10 \mathrm{msec} / \mathrm{channel}$, the cursor is stationary. Moving the switch to the left causes the cursor to move to the left; there are two scanning rates available, with the position near stationary being the slower. Moving the switch to the right moves the cursor to the right in a manner analogous to movement to the left. The initial channels of each subgroup must be selected in sequence from the left. Adjust the cursor until it is in the desired channel. and press the Restart Run button; this causes the given channel number to be read by the computer. If fewer than eight subgroups are used, pressing the "End Sample button saves time by sending the program on to the next section.

This option should be used very rarely. The display feature with the cursor can be reached independently through program DISPL.

To avoid tedious manual entry of information that presumably will be the same for the vast majority of samples, data taking and processing under index numbers $1-5$ is very inflexible. Tabulated below are the subgroup mass assignments; these may not be changed unless the new mass fulfills the same function as the one assigned in the program.

\begin{tabular}{|c|c|c|c|c|c|c|c|c|c|}
\hline Subgrc & bup & .1 & 2 & 3 & 4 & 5 & 6 & 7 & 8 \\
\hline Index & 782 & 233 & 233.5 & 234 & 235 & 236 & 236.5 & 238 & Unused \\
\hline$\therefore "$ & 3 & Unusèd & 233.5 & 234 & 235 & Unused & Unused & 238 & Unused \\
\hline . & 485 & 235 & 236.5 & 238 & 239 & 240 & 241 & 242 & 243. \\
\hline
\end{tabular}

If it is unnecessary to monitor a given mass; entering a sweep factor of zero. in program MSRUN eliminates it both from the sweep and the 
calculations. Unassigned subgroups may be used to monitor any mass, in which case the number of counts collected appears on the first output sheet of program MS but is ignored in further calculations.

For Index $=1$ or 2 (urani um samples, Subgroup 2 (mass 233.5) is used as a measure of background noise and is subtracted from each of the other subgroups. Subgroup 6 (mass 236.5) is used to correct mass 236 for tailing from mass 238; six tenths of the counts in it are subtracted from Subgroup 5 (mass 236). Six tenths is an emplrically drrived at correction factor for two-stage instruments and is the result of 15 years' experience at ORNL. For Index $=1$, masses $234,235,236$, and 238 are used to determine isotopic abundances. Index $=2$ adds 233 to the above list. In addition to isotopic abundances, Index $=1$ calculates the following ratios: $234 / 235,236 / 235,235 / 238$, and $233 /$ sum. The last can be used as a measure of contamination if spiked uranium samples are run frequently. Index $=2$ calculates the same ratios (sum/233 has a different meaning, obviousiy) and lists total uranium as well. Since the field specification for total $U$ is F8.5, values for this ratio between 0.00001 and 99.99999 are the only ones that can be listed individually. Since it is likely that the ratio will exceed 100 on occasion, the averages and standard deviations of both sum/233 and totai uranium are listed a secund time below the main output in $E$ formats.

For Index $=3$ (NBS 500), only the dead time and bias correction are calculated and listed. If an isotopic analysis of NBS 500 is required, Index $=1$ should be used.

For Index $=4$ and 5 ( $p$ lutonium samples), isotopic composition is calculated on the basis of masses 238-242. Mass 236.5 is used as a background monitor, and the number of counts in it is subtracted from all other subgroups. Mass 235 is intended to be used as a measure of uranium contamination. Since the isotopic composition of the uranium would in general be unknown, no correction is made to the 238 peak for its uranium contribution. Mass 243 is used to monitor americium; it is multiplled by 8 and subtracted from mass 241. Mass 244 is not monitored. If it becomes desirable to do so on a routine basis, a program change will be necessary. Since all eight subgroups are already in use, it will be necessary to sacrifice one of the other mass positions in this event. 
In addition to isotopic composition. Index $=4$ or 5 also yields lists of the following ratios: $238 / 239,240 / 239,241 / 239,242 / 239$, and $235 / 238$.

If a sample is to be run that cannot be conveniently accommodated by any of the above schemes, Index $=6$ offers virtually unlimited flexibility at the expense of requiring more: input from the keyboard: masses to be scanned, which subgroups should be used to calculate isotopic composition, which subgroup is to be used as a background correction and which subgroup is to be used as a tailing correction - all these parameters must be entered. A zere (ur Return) entered for ratios to be calculated and subgroups to be used for background and tailing corrections causes these sections of the program to be ignored. The program will not like it, however, if you enter zero for the subgroups to be used in the total.

\subsection{Statistical Treatment of the Data}

Because of its importance; this section is comprised of an outiine of the statistical treatment the mass spectrometric data undergo. This technique has been analyzed by many statisticians and given their approval; in :addition, it is used on the data generated by instruments similar to ORNL.'s at other laboratories.

\begin{tabular}{|c|c|}
\hline Symbol. & Function \\
\hline$i$ & Channel number. \\
\hline$c(i)$ & No. of counts in channel $i$ \\
\hline $\operatorname{cc}(1)$ & $\begin{array}{l}\text { No. of counts in channel } 1 \text { corrected for } \\
\text { coincidence loss. }\end{array}$ \\
\hline j & Mass number。 \\
\hline N & No. of channels to be summed up for mass $j$. \\
\hline$N(j)$ & First channel of mass $j$ \\
\hline$s(j)$ & $\begin{array}{l}\text { Sum of counts for mass } j \text {. Count loss corrected } \\
\text { only. }\end{array}$ \\
\hline $\operatorname{sS}(j)$ & $\begin{array}{l}\text { Count loss and voltage corrected sum of counts } \\
\text { for mass } j \text {. }\end{array}$ \\
\hline$V(j)$ & Voltage :correction factor for mass $j$. \\
\hline$\sigma_{i j}$ & Counting statistic for mass $j$. \\
\hline
\end{tabular}


Symbol ss(k) $k$

$R(1)$

a

b

$\sigma_{R(1)}$ $Q(1)$

n

$\sigma \frac{1}{R(1)}$
Function

Sum or difference of two or more masses $S S(j)$ :. Masses $j$ to be included in $S S(k)$. Specified on program input.

Ratio of two masses or sums of masses.

Numerator of ratio $R(1)$, where a can equal any j.or. $k$.

Denominator of ratio $R(1)$, where $b$ can equal diny $j$ or $k$.

Std. dev. of ratio $R(1)$.

Number of ratios $R(1)$ in an analysis.

Index for ratius $R(1)$ and their corresponding $\sigma$ 's.

Std. dev. of individual ratios $R(.1)$.

Calculation of sum of masses:

$$
\begin{aligned}
& S(j)=: \begin{array}{l}
N(j)+N-1 \\
i=N(j)
\end{array} C C(i) \\
& S S(j)=S(j) \times V(j) \\
& S S(k)=\sum_{j}^{k} S S(j)
\end{aligned}
$$

Calculation of counting statistics (to be used as weighting factors) for individual masses and ratios.

$$
\sigma_{. j}=\sqrt{\varepsilon(j)} \times V(. j)
$$

In the case of a sum or difference of masses, the statistic is:

$$
\begin{gathered}
\sigma_{k}^{\cdot}=\sqrt{\Sigma\left(\sigma_{j}^{2}\right)^{2}} \\
R(1)=\frac{S S(a)}{S S(b)} \\
\sigma_{R(1)}=R(1) \quad\left[\left(\frac{\sigma a}{S S(a)}\right)^{2}+\left(\frac{\sigma b}{S S(b)}\right)^{2}\right]^{\frac{1}{2}}
\end{gathered}
$$


Statistical Analysis

Each ratio for a particular unknown (for example 5/8) will be assigned a: weighting factor $\left(\frac{1}{\sigma R(1)}\right)$ inversely proportional to the counting statistic value calculated abovê.

The weighted grand average $\bar{R}(1)$ for the particular unknown shal1 be calculated as:

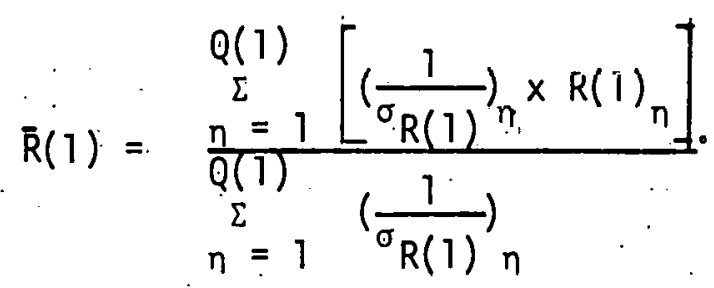

The standard deviation for the distribution of individuat ratios shall be calculated as:

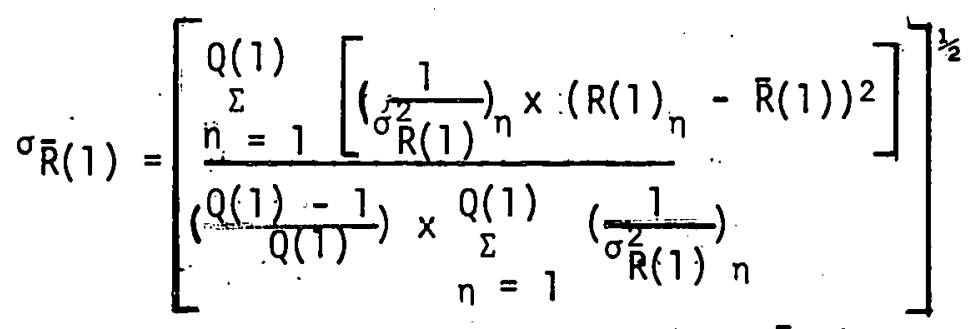

If $\left|R(1)_{n}-\bar{R}(1)\right|>\sigma \dot{R}(1) \times$ table value of $\frac{\mid R(1)_{n}-\bar{R}(1)}{\dot{\sigma}_{\bar{R}}(1)}$. that particular ratio $R(1)_{n}$ will be rejected. This test will be applied to all $Q(1)$ ratios $R(1)$. Those ratios not rejected will be considered in the recalculation of $\bar{R}(1)$ and $\sigma \bar{R}(1)^{\circ}$ The rejection of data criteria will not be reapplied in the recalculation.

Table for Ratio Test

$\begin{array}{cc}\frac{Q_{1}}{4} & \frac{R(1)_{n}-\bar{R}_{1}}{1.53} \\ 5 & 1.64 \\ 6 & 1.73 \\ 7 & 1.80\end{array}$




\begin{tabular}{cc}
${ }_{1}{ }_{1}$ & ${ }_{1 n}-\bar{R}_{1}$ \\
\hline 8 & 1.87 \\
9 & 1.97 \\
10 & 1.97 \\
11 & 2.01 \\
12 & 2.05 \\
13 & 2.08 \\
14 & 2.11 \\
15 & 2.14 \\
16 & 2.16 \\
17 & 2.18 \\
18 & 2.20 \\
19 & 2.22 \\
20 & 2.24 \\
21 & 2.26 \\
22 & 2.27 \\
23 & 2.29 \\
24 & 2.30 \\
25 & 2.32
\end{tabular}

Finally, the standard error of the mean (which is the value reported along with the grand average) shall be calculated as:

Standard error $(\bar{R}(1))=\frac{\sigma_{\bar{R}}(1)}{\sqrt{Q(1)}}$

6.7 Auxiliary Programs: FILST, MSDAT, MSREP, DISPL

FILST is a program that allows insertion of a new dead time, voltage corrections per mass, masses, sweep factors, and number of cycles into disk file VCTSF (Section 6.2 .3 ). It also allows insertion of new spike isotopic compositions into file SPISO (Section 6.2.4). Keyboard instructions should be self-explanatory. 
MSSAT allows one to generate an artificial subgrouped mass spectrum for program testing. It also can be used to initialize CHDATA and MSSAM files (Sections 6.2.1 and 6.2.2) when that is necessary. Keyboard instructions should be self-explanatory.

MSREP outputs a report of samples of the same type from the MSOUT file. Isotopic abundances, ratios, and standard deviations are included. Samples whose data are no longer needed are erased from the file in this program. It is also used to initialize files MSBKP and MSOUT (Sections 6.2.5 and 6.2.6). Keyboard instructions should be self-explanatory.

DISPL reads a specified CHDATA file from the disk and displays successive runs on the oscilloscope. The cursor is also available. Press the End Sample button to read in the next run.

\subsection{Subroutines}

In addition to mainline programs, there are a few subroutines:

LINE: Keeps track of the current line number on the output sheet and advances to a new page after 62 lines have been written. Calling form: CALL LINE (NLIN, N); NLIN is the current line number and $N$ is the number of lines NLIN is to be increased. If $N=0$, the DEC writer will advance to a new page.

DATSW: Interrogates a given console switch and returns a $l$ if it is down and 2 if it is up. Calling form: $\operatorname{CALL~DATSW~(~} n$, ivar) where $n$ is the console switch number (0-15) and ivar is an integer variable that will have a value of 1 or 2 . This subroutine is in assembly language.

FDATE: Reads the current date from the DEC file. Calling form: CALL FDATE (ivar); ivar is an integer variable that must be dimensioned ( 3 ). It contains the day, month, and year in that order. An assembly language subroutine.

DISP1: An assembly language subroutine that controls oscilloscope display of channel data in programs DISPL and MS. It also operates the cursor.

These four subroutines are incorporated in library file LIB. When linking any ORNL-written program, it is desirable to specify LIB as an input 
file to avoid an error message (usually UNDEF GLOBLS). See Section 6.5 for an example of how LIB should be specified. 


\section{CHAPTER 7: SUMMARY}

It is hoped that most difficulties you will encounter in operating this instrument are covered in the preceding chapters and that the instructions concerning routine operation are clear and thorough enough to allow you to master it with comparative ease. Inevitably, however, some problem will develop that is not mentioned; if you are unable to correct it yourself, do not hesitate to get in contact with us at ORNL. The instrument is a complex one, and it takes several years to become truly expert in its operation.

Although recommended sample loadings should be followed when possible, the instrument is capable of analyzing samples much smaller if due care is exercised. Lower count rates than those suggested will have to be accepted. We have successfully obtained isotopic analyses of uranium samples of about $10^{-12}$ grams on a routine basis using special techniques and experienced operators. Indeed, too much sample is a more common problem than too little. Try to avoid loading more than $200 \mathrm{ng}$ of $U$, or the time required to achieve beam stability and spectrum cleanliness will become excessive.

Because of the high abundance sensitivity due to the two stages of magnetic deflection and the multiple scanning of minor isotopes possible through the Sweep Control panel, precision and accuracy of minor isotope abundances should be considerably better than on other instruments using comparable sample size. The ultimate abundance that can be measured with this instrument is about $1 \mathrm{ppm}$. An example demonstrating this order of abundance sensitivity is given in Figure 7.1. There are about 120,000 counts per channel in the mass 238 position. Since there are about 10 channels in the peak top, there are about $1.2 \times 10^{6}$ counts of 238 collected. There is at most one count in the 237 position (full scale in the upper photograph is 127 , and individual counts are visible above the base line), which gives an abundance sensitivity of at least $1.2 \times 10^{6}$. These data were collected with the slits in their normal operating positions, and exemplify the results that should be obtainable from clean samples.

ORNL has added an electrostatic analyzer to one of their instruments to make a three-stage mass spectrometer. ${ }^{(9)}$ Abundance sensitivity is 

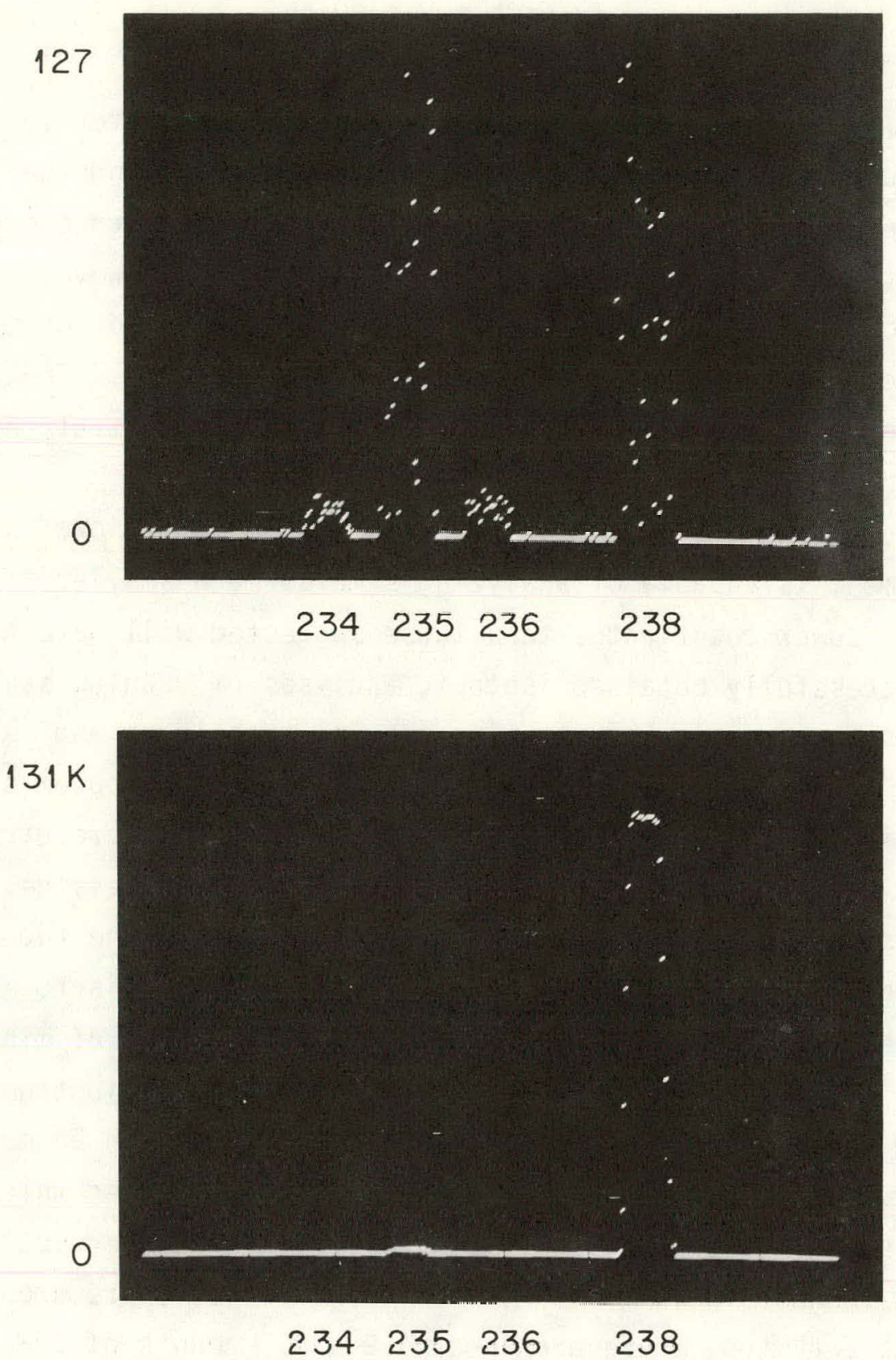

Fig. 7.1 Abundance sensitivity measurement. 
enhanced by about a factor of 1000, and the lowest abundance yet quoted on the instrument is $0.0008 \mathrm{ppm}(0.8 \mathrm{ppb})$. Should the International Atomic Energy Agency ever desire to add such an analyzer to their instrument, it is a relatively simple matter to do sö. 


\section{REFERENCES}

1. A. E. Cameron, W. H. Christie, H. S. McKown, W. T. Rainey, and D. H. Smith, U. S. Atomi c Energy Commission Report ORNL-4643, Oak Ridge, Tennessee, 1971.

2. F. A. White and T. R. Collins, Appl. Specty. $\underline{8}, 169$ (1954).

3. A. 0. Nier, Rev. Sci. Instr. 18, 398 (1947).

4. W. H. Christie and A. E. Cameron, Rev. Sci. Instr, 37, 336:(1966).

5. C. R. Lagergren and J. J. Stoffels, Int. J. Mass Spec. and Ion Phys. 3 , 4î̉ (1970).

5. R. L. Walker, R. E. Eby, C. A. Pritchard, and J. A. Carter, Anal. letters Z. 563 (1974).

7. A. E. Cameron, Actinides Rev. 1, 299 (1969).

8. A. E. Cameron, D. H. Smith, and R. L. Walker, Anal. Chem. 41, 525 (1969).

9. D. H. Smith, W. H. Christie, H. S. Mckown, R. L. Walker, and G. R. Herte1, Int. J. Mass Spec. and Ion Phys. 10, 343 (1972). 


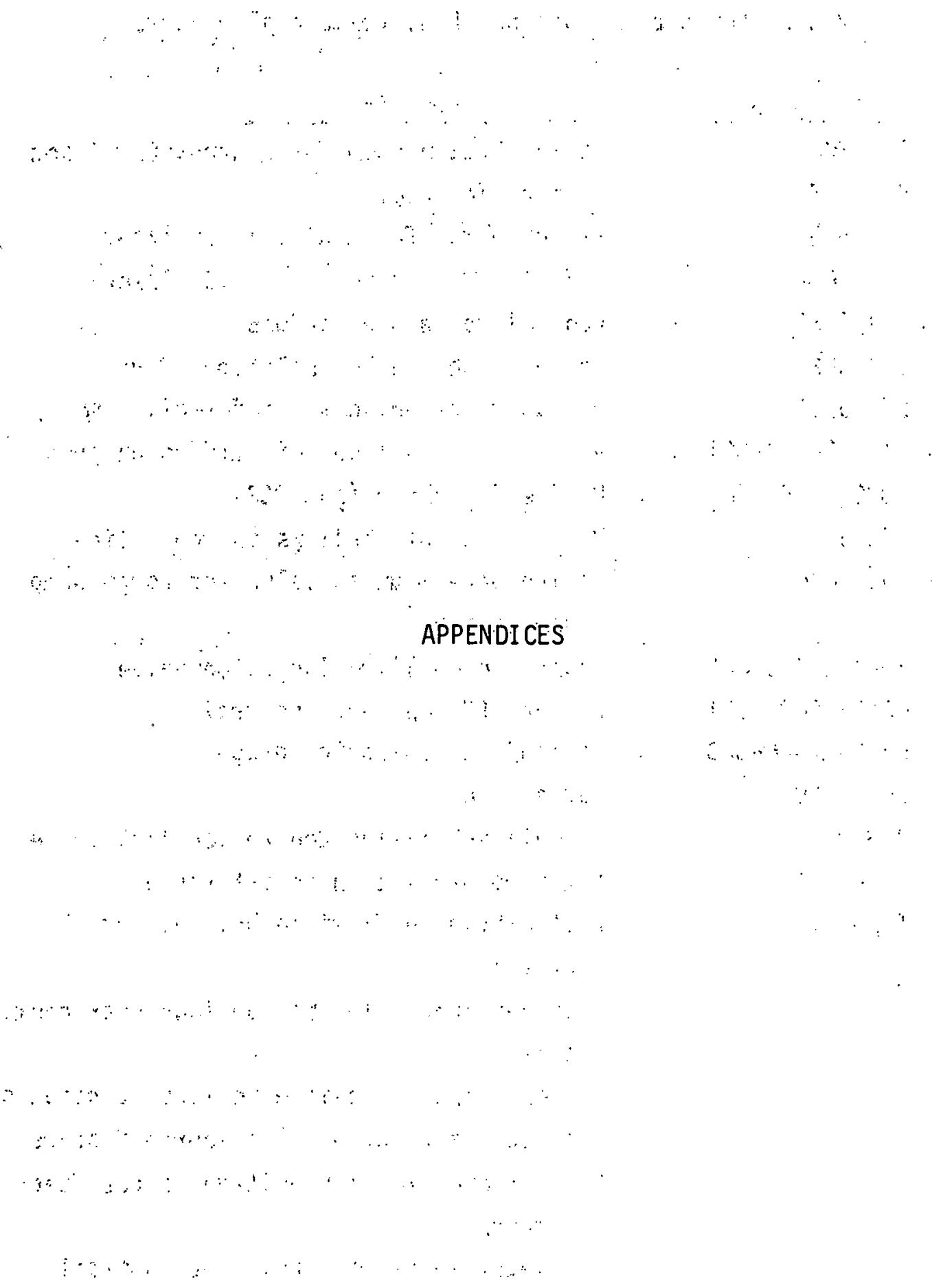




\section{APPENDIX 1}

Vacuum Components Obtained From Commercial Vendors

\begin{tabular}{|c|c|}
\hline No. & Catalog No. \\
\hline 1 & $912-7000$ \\
\hline 1 & $921-0066$ \\
\hline 2 & $911-5032$ \\
\hline 1 & y11-5U34 \\
\hline 1 & $921-0062$ \\
\hline 1 & $951-5027$ \\
\hline 1 & $951-5091$ \\
\hline 1 & $0189-F 8999-301$ \\
\hline 1 & $0332-F 9453-302$ \\
\hline 1 & $952-5054$ \\
\hline 2 & $952-5010$ \\
\hline 1 & $208001-013-013$ \\
\hline 1 & $0840-K 0035-301$ \\
\hline 2 & $0563=k 24.66-303$ \\
\hline 1 & $952-5050$ \\
\hline 1 & 203-015 \\
\hline 1 & $281-6051$ \\
\hline 4 & Type DD \\
\hline
\end{tabular}

Description

Varian Vacion pump for source, $140 \mathrm{l} / \mathrm{sec}$

Control for above

Vacion pumps for analyzer, $301 / \mathrm{sec}$

" " " " ,60 1/Eec

Control for above Vacions

Varian right angle isolation valve

Varian right angle valve for ofl pump

Varian M-2 $175 \mathrm{l} / \mathrm{sec}$ oil diffusion pump

Baffle for above (NRC 332)

Varian flexible bellows in rough line

Varian edge mounted valve for rough pump and venting

Granville Phillipe isolation valve

Varian/NRC ion gauge control

Varian/NRC ionization gạilge

Varian croes

Granville-Phillips controlled leak valve

Ultek rotary motion feed-through

Fulton-Sylphon flexible bellows for slit drivers

Fulton-Sylphon flexible bellows near center slit

Fulton-sylphon fiextble bellows at detector American Lava Co. alumina source spacers

U. S. Stoneware high voltage source feedthroughs

Pyrometer Instrument Co., Inc. optical pyrometer

RCA electron multiplier 


\begin{tabular}{|c|c|c|c|}
\hline No. & Catalog No. & & Description \\
\hline 1 & $954-5127$ & & Varian viewing port \\
\hline 2 & Model 5311 & $\therefore$ & Varian/NRC thermocouple; gauges \\
\hline 1 & $951-5205$ & & Varian gate valve \\
\hline
\end{tabular}




\section{APPENDIX 2}

Electronic Components Obtained from Commercial Vendors

Model No.

$410 \mathrm{~B}$

$408 \mathrm{~B}$

604

$6268 B$

436

$401 \mathrm{~A}$

104550

PDP-11

LA36

RK11

TA11

$11 \mathrm{H}$
Description

Fluke $10 \mathrm{kV}$ source power supply

Fluke $6 \mathrm{kV}$ multiplier power supply

Tektront $x$ uscilloscope

Hewlett-Packard magnet power supply

ORTEC $100 \mathrm{MHz}$ discriminator

ORTEC NIM-bin power supply

ARL signal amplifiers

Digital Equipment Corp. computer

DEC writer

DEC disk

DEC cassette

DEC interface 
American Lava Co., Chattanooga, TN

Applied Research Laboratories (ARL), P. O. Box 129, Sunland; CA 91040 Digital Equipment Corp., Maynard, MA 01754

Fluke Manufacturing Co., P. O. Box 7428, Seattle, WA 98113

Ful ton-Sylphon. Inc, 2318 kingston Pike, SW, Kiruxulilie, TN Granville-Phillips Co.., 5675 East Arapahoe Ave., Boulder, CO . 80303

Hewlett-Packard, Inc, 3003 Scott Blyd., Santa Clara, CA 95050

ORTEC, 100 Midl and Road, Oak Ridge, TN. 37830

Pyrometer Instruments $\mathrm{Co}_{0}$, Inc., Bergenfield, $\mathrm{NJ}$

RCA, New Holl and Ave., Lancaster, PA 17604

Tektronix, Inc., P. 0. Box 500, Beaverton, OR 97005

Ul tek Corp., P. 0. Box 10920, Palo Alto, CA 94303

United States Stoneware, Alite Division, P. O. Box 119, Orrville, $\mathrm{OH}$ Varian/NRC, Inc。, 611 Hansen Way, Palo Alto, CA 94303

Many of these manufacturers have European offices, and several have branches in Vienna. 
APPENDIX 4

Vacuum Component Print Index

Tandem $30 \mathrm{~cm}$. Mass Spectrometer

Contents of Drawing

Overall assembiy, top view

Print Number

Ion source can assembiy

M2E90647-1

Ion source can, construction details

$-2$

Ion source details and assembly

$-3$

Flight tube/source isolation valve

Contactor bracket details and assembly

$-5$

Filament bracket and wheel details and assembly

Whee 1 bracket and rotary motion feedthrough -8

Slit can and collimating slit assembly

Slit can details $\quad-10$

Collimating slit detalis -11

Detector housing/flexible bellows details and assembly -12

Support bracket/spectrometer components assembly -13

Support bracket details - 1st stage -14

" " - 2nd stage -15

Magnet EM5 3099

Coil form EM53111 


\section{APPENDIX 5}

\section{ORNL-Built Electronic Components Print Index}

\section{Tandem $30 \mathrm{~cm}$. Mass Spectrometer}

Contents of Drawing

Magnet balance

Sweep control

Oscilloscope control

Power distribution panel

Source divider

Sample filament supply

Sweep amplifier

Multiplier divider

Ion current scaler
Print Number

REF-110

REF-204A

$-204 B$

$-204 C$

REF-203

REF- 148

REF-160-1

REF-205

REF-201A

$-201 B$

REF-206

REF-202 
THIS PAGE

WAS INTENTIONALIY

LEFT BLANK 
1-2. Central Research Library

3-4. Laboratory Records Department

5. ORNL-RC

6. ORNL-Y-12 Technical Library Document Reference Section

7. J. C. Barton

8. N. K. Bernander

9. E. R. Bowers

10. A. E. Cameron (Consultant)

11. D. Co Canada

12-31. J. A. Carter

32-43. W. H. Christie

44. Fo L. Culler

45. D. L. Donohue

46. R. E。 Eby

47. J. C. Franklin

48. W. D. Harman
49. R. F. Hibbs

50. 0. H. Howard

51-62. H. S. Mckown

63. H. Postma

64. C. A. Pritchard

65. W. T. Rainey

66. W. W. Rice

67. W. D. Shults

68-79. D. H. Smith

80. L. A. Smith

81-88. R. L. Walker

89. J. R. Walton

90. J. C. White

91. W. J. Wilcox

92. A. Zucker

93. ORNL Patent Office

EXTERNAL DISTRIBUTION

94. J.H. Menze 1, ACDA

95. Lorin Stieff, ACDA

96-100. J. R. Sites, International Atomic Energy Agency

101. Research and Technical Support Division, ERDA-ORO

102-128. Technical Information Center, Oak Ridge (NTIS - 25 copies) 